\title{
Nonlinear Backstepping with Integral Action for Wind Power Plant Based on Doubly Fed Induction Generator Connected to the Non-Ideal Grid
}

\author{
Elmostafa Chetouani ${ }^{1}\left[\right.$ ] Youssef Errami $^{1} \cdot$ Abdellatif Obbadi $^{1} \cdot$ Smail Sahnoun $^{1} \cdot$ Boaz Wadawa $^{1}$
}

Received: 13 April 2021 / Accepted: 19 January 2022 / Published online: 10 February 2022

(c) The Author(s), under exclusive licence to Springer Nature Singapore Pte Ltd. 2022

\begin{abstract}
This paper suggests the integral Backstepping nonlinear control of the wind power plant based on the Doubly-Fed Induction Generator connected to the grid in normal conditions and under parameters variation. The stator of the generator is explicitly linked with the electrical network. However, the rotor winding is associated with the grid via a bidirectional AC/DC/AC converter. The purpose of this paper is to control the powers produced by a variable speed wind turbine, pilot the exchanged power between the system and the electrical grid and regulate the voltage of the continuous bus capacitor. Besides, the suggested method is applied to establish the maximum power tracking strategy. The Backstepping control law is established founded on the stability of the Lyapunov function. The proposed control is performed and compared with the conventional Backstepping and the indirect field-aligned control. Discussion of the principle and elaboration of the Integral Backstepping laws are achieved. Performance tests are realized by MATLAB/ Simulink software. From the simulation results, the effectiveness and superiority of the Integral Backstepping are well demonstrated.
\end{abstract}

Keywords DFI generator · Integral Backstepping control $\cdot$ Lyapunov function $\cdot$ MPPT $\cdot$ Wind power plant

\section{Introduction}

In the world as it is today and without electricity, daily life would be difficult to imagine. Therefore, It is necessary to produce electric energy efficiently and continuously. Following the terrible damage caused by the electricity production on the environment using fossil fuel energy sources such as coal, oil, and natural gas, renewable energy based on inexhaustible energy sources remains the best solution to replace the existing energy sources [1]. Recently, wind energy is considered clean, sustainable energy, and economically reasonable. It has known considerable development and exploitation, thanks to the strong growth in the research domain. The

This article belongs to the Topical Collection: Modern Approaches for Efficient Energy Systems

Elmostafa Chetouani

chetouani.m@ucd.ac.ma

1 Laboratory: Electronics, Instrumentation and Energy Team: Exploitation and Processing of Renewable Energy, Department of Physics, Faculty of Sciences, University of Chouaib Doukkali, El Jadida, Morocco wind energy conversion system has several configurations. Figure 1 represents the studied system configuration, which is widely used and dedicated to wind energy applications. The wind turbine shaft is coupled to the Doubly-Fed Induction Generator (DFIG) through the gearbox to adapt the slow speed to the high speed. DFIG stator is directly connected to the electrical network. However, the rotor is branched to the grid through two pulse width modulation converters cascaded via a capacitor. The Rotor Side (RS) converter permits the control of the generated power by the generator, and the Grid Side (GS) converter maintains the DC-link voltage constant and controls the injected reactive power into the grid [2]. The main advantage of the wound rotor induction generator integrated with the Wind Power Plant (WPP) is that the ability to use a partial sized converter in the rotor to control the power and ensure grid stability [3, 4].

The produced mechanical power depends on the characteristics of each turbine and the wind variable speed. Consequently, tracking the maximum power generated is required when the profile wind speed changes. Many control schemes have been developed to perform the Maximum Power Tracking (MPT). In this work, the Tip Speed Ratio (TSR) algorithm is designed to pilot the generator speed 


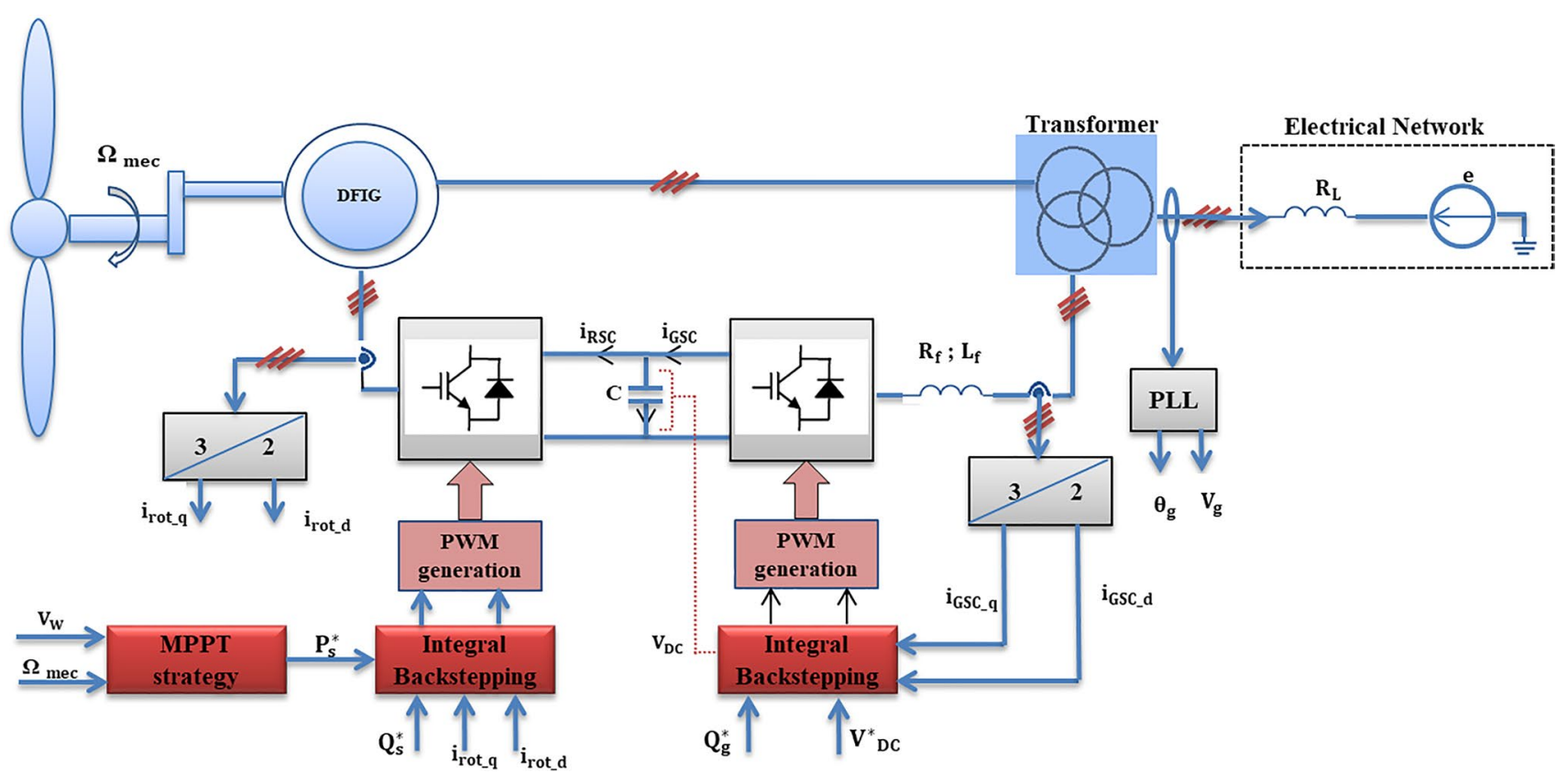

Fig. 1 Synoptic scheme of WPP based on DFI generator

rotation. More details about the MPT strategies are given by Mousa et al. [5]. The TSR strategy can be classified into two categories [6]. The first one has required knowledge of the characteristic aerodynamic curve of wind turbine speed, and the second one does not need any information about wind speed to generate the optimal speed rotation of the rotor.

The vector control (VC) is widely employed for controlling the rotor wound induction generator because it can permit a separate control of the reactive and active power. The Direct and Indirect Field-Aligned Control (D/IFAC) are variants of the VC. Bouderbala et al. [7] have proposed a comparative study between direct and indirect control based on Proportional-Integral (PI). The authors have shown that indirect control presents satisfactory performance than direct vector control. The PI controller gains values are based on the generator parameters, which are subject to many constraints, such as parameters uncertainties due to temperature increasing, defect occurring in the generator, and machine saturation, that could deflect the system from its optimum operating [8]. That is why many techniques have been proposed and developed for dealing with the vector control drawbacks, such as Backstepping and Sliding Mode Control (SMC). The particularity of these two techniques is that they are based on the stability of the Lyapunov function and are simple to implement. Direct Torque Control (DTC) is another commonly used control method for controlling torque and flux independently and by going so managing active and reactive power [9]. The presence of significant ripples and the variable switching frequency, which are the main drawbacks of this approach. These disadvantages can degrade the quality of the output power. Therefore, Cherifi et al. [9] have proposed the Space Vector Modulation to reduce the oscillations observed in the created torque (SVMDTC). Additionally, Y Benevieri et al. [10] have suggested the synchronous DTC for reducing the harmonic spectrum content in the torque. The SMC has been proposed to control the DFI generator $[11,12]$. However, its utilization is generally accompanied by the chattering phenomenon, which is the major drawback of SMC [13]. A modified form of the conventional sliding mode control for controlling the DFIG and reducing the chattering, which is called Terminal Sliding Mode Control (TSMC), is proposed and compared with SMC and vector control by Zahedi et al. [11]. Based on a nonlinear terminal sliding surface, the TSMC ensures a faster convergence of the system. Kelkoula et al. [14] have proposed the super twisting sliding mode algorithm, which is based on the sliding surface, for the DFIG-based wind turbine. Ameliorating the time converge and reducing the chattering are the powerful points of this technique. However, the robustness test shows that the variation of the generator settings has an impact on the response time, and significant ripples are observed in the findings. On the other hand, Sami et al. [15] have presented a super twisting fractional-order terminal sliding mode control for controlling the converters of the DFIG. The authors have compared the proposed technique with the fractional-order sliding mode and the standard sliding mode control. The suggested has shown an advantage in terms of minimizing the chattering problem. However, Chojaa et al. [16] have proposed the Integral Sliding Mode (ISM) as another alternative method of the Sliding 
Mode to control the powers and deal with the drawback of SMC. However, the system's performance in terms of the responses time, static errors, and overshoot are evaluated as unsatisfactory. In addition, the quality of the results may be lowered if the surface sliding is chosen improperly.

Taking into consideration the prior studies, the Backstepping technique, which has been utilized by many researchers, is a nonlinear approach that is used to deal with the nonlinearity of complex systems. Dbaghi et al. [17] have applied Backstepping to control the Rotor Side Converter and have tested the robustness by varying only and simultaneously the rotor inductance and resistance by $50 \%$ of their rated values. Results are compared to those obtained by indirect power control. Furthermore, El Mourabit et al. [18] have applied the Backstepping control for regulation of the PMSG wind turbine based on the real wind profile of the Dakhla-Morocco city. In addition, Mensou et al. [19] have established Conventional Backstepping (BSC) to control the whole wind energy conversion system. Besides, Nadour et al. [20] have established a comparative study between the Backstepping controller and the vector control based on PI Controller for DFIG-based Wind Turbine. Additionally, Bossoufi et al. [21] have designed a robust Adaptive Backstepping Control, which is based on adaptive pole placement control, to control the powers of the DFIG. By studying previous works, the authors have proved the excellent performance of the nonlinear Backstepping control for regulating the produced power. However, variations in generator characteristics caused by rotor winding warming or machine saturation can affect the Backstepping controller's performance. Many researchers have recently proposed the Integral Backstepping Controller (IBSC) as an alternative to Backstepping to overcome this issue. El Malah et al. [22] have proposed the integral Backstepping (IBSC) to get the Maximum Power Tracking (MPT) and control the unit power factor of a Hybrid Wind-Photovoltaic System connected to the grid in normal conditions.

Unlike the contributions presented by Dbaghi et al. [17] and El Malah et al. [22], our work proposes a complete and detailed study of the Integral Backstepping Controller for regulating the wind power plant in many circumstances, including MPT strategy. The advised technique is compared to the conventional Backstepping and the indirect vector control under parameters variation to test its robustness.

The main contribution of this paper is to test the robustness integral Backstepping control against different generator parameters variation. Besides, a comparative analysis is established between the Backstepping with integral action (IBSC), Conventional Backstepping (BSC), and the Open Loop Indirect Field-Aligned Control (IFAC) strategies for controlling the converters of the wind energy system based on the DFI generator. Likewise, the MPT with speed regulation is established based on these three studied techniques. The paper is organized into the following sections:

- Second section presents the modeling of the WPP;

- Third section discusses the MPT with a speed regulation strategy computed by the PI controller;

- Forth section proposes the control of the active and reactive powers by using the IBSC, BSC, and IFAC;

- Fifth section proposes the control of the MPT, DC link voltage, and stator powers by using the IBSC and BSC;

- Sixth section discusses and compares the simulation results in normal conditions and under generation variation;

- And finally, the conclusion is presented in the seventh section.

\section{Wind Power Plant modeling}

\section{Model of the Wind Turbine}

The turbine mechanical power $\left(\mathrm{P}_{\mathrm{Tu}}\right)$ is expressed as [23]:

$\mathrm{P}_{\mathrm{Tu}}=\frac{1}{2} \cdot \mathrm{C}_{\mathrm{p}}(\lambda, \beta) \cdot \rho \cdot \pi \cdot \mathrm{R}^{2} \cdot \mathrm{V}_{\mathrm{w}}^{3}$

The mechanical torque $\mathrm{T}_{\mathrm{Tu}}$ is written as below:

$\mathrm{T}_{\mathrm{Tu}}=\frac{\mathrm{P}_{\mathrm{Tu}}}{\Omega_{\mathrm{Tu}}}$

Where $\mathrm{V}_{\mathrm{w}}$ is the wind velocity, $\rho$ is the air density $(\mathrm{kg} /$ $\mathrm{m}^{3}$ ), R is the blade ray (m), $\Omega_{\mathrm{Tu}}$ is the angular velocity of the turbine, and $C_{P}$ represents the performance factor of the turbine. $\mathrm{C}_{\mathrm{p}}$ can be formulated as [24]:

$\mathrm{C}_{\mathrm{P}}(\beta, \lambda)=[0.5-0.0167 .(\beta-2)] \cdot \sin \left(\frac{\pi(\lambda+0.1)}{18.5-0.3 .(\beta-2)}\right)-0.00184 .(\lambda-3) .(\beta-2)$

This coefficient is calculated by the tip speed $\lambda$ and the angle $\beta$ of the blade pitch. The latter is fixed to $\beta=2^{\circ}$ for having $\mathrm{C}_{\mathrm{Pmax}}$. Eq. (4) defines the expression of $\lambda[23,25]$ :

$\lambda=\frac{\mathrm{R} \cdot \Omega_{\mathrm{Tu}}}{\mathrm{V}_{\mathrm{w}}}$

\section{Model of the Gearbox}

Equation (5) presents the mechanical equation of the system, taking into consideration that the overall mechanical dynamics are brought back to the turbine shaft $[23,25]$ : 
$\mathrm{J}_{\mathrm{tot}} \cdot \frac{\mathrm{d} \Omega_{\mathrm{mec}}}{\mathrm{dt}}+\mathrm{f} . \Omega_{\mathrm{mec}}=\mathrm{T}_{\mathrm{g}}-\mathrm{T}_{\mathrm{em}}$

Where

$\mathrm{T}_{\mathrm{g}}=\frac{T_{\mathrm{Tu}}}{\mathrm{G}_{B}}=\frac{\mathrm{T}_{\mathrm{Tu}}}{\mathrm{G}_{\mathrm{B}}}$ and $\mathrm{G}_{\mathrm{B}}=\frac{\Omega_{\mathrm{mec}}}{\Omega_{\mathrm{Tu}}}$

Where $\mathrm{J}_{\text {tot }}$ is the overall inertia of wind energy system, $\mathrm{T}_{\mathrm{Tu}}$ is the turbine torque, $\mathrm{T}_{\mathrm{Tem}}$ is the electro-magnetic torque of the DFI generator, $\mathrm{f}$ is the overall viscous coefficient of friction, $\Omega_{\mathrm{mec}}$ is the rotational speed at the rotor shaft of the gearbox $(\mathrm{rad} / \mathrm{s})$ and $\mathrm{G}_{\mathrm{B}}$ is the gearbox multiplier.

\section{Model of the DFI Generator}

The Park transformation allows simplifying the general electrical model, which is determined by the following equations. Stator and rotor voltages equations are $[12,26]$ :

$\left\{\begin{array}{l}\mathrm{V}_{\mathrm{gd}}=\mathrm{R}_{\text {sta }} \cdot \mathrm{i}_{\text {sta_d }}+\frac{\mathrm{d} \psi_{\text {sta_d }}}{\mathrm{dt}}-\omega_{\mathrm{g}} \cdot \Psi_{\text {sta_q }} \\ \mathrm{V}_{\mathrm{gq}}=\mathrm{R}_{\text {sta }} \cdot \mathrm{i}_{\text {sta_q }}+\frac{\mathrm{d} \psi_{\text {sta_q }}}{\mathrm{dt}}-\omega_{\mathrm{g}} \cdot \Psi_{\text {sta_d }} \\ \mathrm{V}_{\text {rot_d }}=\mathrm{R}_{\text {rot }} \cdot \mathrm{i}_{\text {rot_d }}+\frac{\mathrm{d} \psi_{\text {rot_d }}}{\mathrm{dt}}-\omega_{\text {rot }} \cdot \Psi_{\text {rot_q }} \\ \mathrm{V}_{\text {rot_q }}=\mathrm{R}_{\text {rot }} \cdot \mathrm{i}_{\text {rot_q }}+\frac{\mathrm{d} \psi_{\text {rot_q }}}{\mathrm{dt}}-\omega_{\text {rot }} \cdot \psi_{\text {rot_d }}\end{array}\right.$

Where $\mathrm{V}_{\text {rot }}$ and $\mathrm{V}_{\mathrm{g}}$ is the rotor and grid voltage; $\mathrm{i}_{\text {sta }}$ and $\mathrm{i}_{\text {rot }}$ are the currents; $\psi_{\text {sta }}$ and $\psi_{\text {rot }}$ are the flux; $\mathrm{R}_{\text {sta }}$ and $\mathrm{R}_{\text {rot }}$ are the resistances; $\omega_{\mathrm{g}}$ and $\omega_{\text {rot }}$ are the angular frequencies; $\mathrm{L}_{\text {sta }}$ and $\mathrm{L}_{\mathrm{rot}}$ are the inductances; $\mathrm{L}_{\mathrm{m}}$ is the Mutual inductance. The "rot" and "sta" denote the rotor and stator, respectively. The electro-magnetic torque can be expressed as follows [12]:

$\mathrm{T}_{\mathrm{em}}=-\mathrm{p}_{\mathrm{p}} \cdot \frac{\mathrm{L}_{\mathrm{m}}}{\mathrm{L}_{\text {sta }}}\left(\mathrm{i}_{\text {rot_q }} \cdot \psi_{\text {sta_d }}-\mathrm{i}_{\text {rot_d }} \cdot \psi_{\text {sta_q }}\right)$

Where $\mathrm{p}_{\mathrm{p}}$ is the number of generator pole pairs.

The stator powers are expressed as follows [7]:

$\mathrm{P}_{\mathrm{s}}=\mathrm{V}_{\mathrm{gd}} \cdot \mathrm{i}_{\mathrm{sta} \_\mathrm{d}}+\mathrm{V}_{\mathrm{gq}} \cdot \mathrm{i}_{\mathrm{sta} \_\mathrm{q}}$

$\mathrm{Q}_{\mathrm{s}}=\mathrm{V}_{\mathrm{gq}} \cdot \mathrm{i}_{\text {sta_d }}-\mathrm{V}_{\mathrm{gd}} \cdot \mathrm{i}_{\text {sta } \_\mathrm{q}}$

\section{Maximum Power Point}

During the normal functioning of the wind turbine, the maximum power control method is developed to exploit the energy available in the wind as much as possible. The MPT method with mechanical speed control is established. This technique consists of maintaining the generator speed at its reference, which is maximized when the $\mathrm{C}_{\mathrm{p}}$ is optimal. The electro-magnetic torque $\left(\mathrm{T}_{\mathrm{em}}\right)$ developed by DFI Generator is equal to its reference value imposed by the control defined as [27]:

$\mathrm{T}_{\mathrm{em}}=\mathrm{T}_{\mathrm{em}-\mathrm{opt}}$

The optimal electro-magnetic torque $\mathrm{T}_{\mathrm{em}-\mathrm{opt}}$ for obtaining a rotation speed equal to the optimal speed is given as follows:

$\mathrm{T}_{\mathrm{em}-\mathrm{opt}}=\left[\mathrm{K}_{\mathrm{p}-\mathrm{mppt}}+\mathrm{K}_{\mathrm{i}-\mathrm{mppt}} \cdot \frac{1}{\mathrm{~S}}\right] \cdot\left[\Omega_{\mathrm{mec}-\mathrm{opt}}-\Omega_{\mathrm{mec}}\right]$

Where $\mathrm{K}_{\mathrm{p}-\mathrm{mppt}}$ and $\mathrm{K}_{\mathrm{i}-\mathrm{mppt}}$ are the PI controller gains. The optimal speed $\left(\Omega_{\mathrm{mec}-\mathrm{opt}}\right)$ is [27] :

$\Omega_{\mathrm{mec}-\mathrm{opt}}=\mathrm{G}_{\mathrm{B}} \cdot \Omega_{\mathrm{Tu}-\mathrm{opt}} ;$ With $\Omega_{\mathrm{Tu}-\mathrm{opt}}=\frac{\mathrm{V}_{\mathrm{w}} \cdot \lambda_{\mathrm{opt}}}{\mathrm{R}}$

\section{Determination of the PI gains for MPT}

The PI controller parameters are determined by the pole compensation method. The time constant of the system $\left(\mathrm{T}_{\text {sys }}\right)$ is:

$\mathrm{T}_{\text {sys }}=\frac{\mathrm{J}_{\text {tot }}}{\mathrm{f}}$

The gains of the controller are expressed as:

$\mathrm{K}_{\mathrm{i}-\mathrm{mppt}}=\frac{1}{\tau . \mathrm{f}}$ And $\mathrm{K}_{\mathrm{p}-\mathrm{mppt}}=\frac{-\mathrm{K}_{\mathrm{i}-\mathrm{mppt}} \mathrm{J}_{\mathrm{tot}}}{\mathrm{f}}$; with $\tau=\frac{\mathrm{T}_{\text {sys }}}{1000}$

\section{Indirect Field-Aligned Control Strategy}

\section{Rotor Side (RS) Converter Control}

To command independently the powers of generator and to deal with the coupling problem of the system, the indirect vector control is applied. In this paper, the powers are controlled in the open loop and the rotor currents are controller in the closed-loop. Stator flux is considered constant and is aligned according to d-axis. The stator resistance is neglected and the stator voltage equation can be simplified as [7]:

$\Psi_{\text {sta_d }}=\psi_{\text {sta }}, \psi_{\text {sta_q }}=0 ; \mathrm{V}_{\text {gd }}=0 \mathrm{~V}_{\text {gq }}=\mathrm{V}_{\mathrm{g}}=\omega_{\mathrm{s}} \cdot \psi_{\text {sta }}$

By using Laplace Transform, the equations of the rotor voltages can be expressed as [7]:

$\mathrm{V}_{\text {rot_d }}=\left[\mathrm{R}_{\text {rot }}+\left(\mathrm{L}_{\text {rot }}-\frac{\mathrm{L}_{\mathrm{m}}{ }^{2}}{\mathrm{~L}_{\text {sta }}}\right) \cdot \mathrm{s}\right] \mathrm{i}_{\text {rot_d }}-\mathrm{g} \cdot \mathrm{\omega}_{\mathrm{g}}\left(\mathrm{L}_{\text {rot }}-\frac{\mathrm{L}_{\mathrm{m}}{ }^{2}}{\mathrm{~L}_{\text {sta }}}\right) \mathrm{i}_{\text {rot_q }}$

$\mathrm{V}_{\text {rot- }}=\left[\mathrm{R}_{\text {rot }}+\left(\mathrm{L}_{\text {rot }}-\frac{\mathrm{L}_{\mathrm{m}}{ }^{2}}{\mathrm{~L}_{\mathrm{sta}}}\right) \cdot s\right] \mathrm{i}_{\text {rot } \_\mathrm{q}}+\mathrm{g} \cdot \omega_{\mathrm{g}}\left(\mathrm{L}_{\text {rot }}-\frac{\mathrm{L}_{\mathrm{m}}{ }^{2}}{\mathrm{~L}_{\text {sta }}}\right) \mathrm{i}_{\text {rot_d }}+\mathrm{g} \frac{\mathrm{V}_{\mathrm{g}} \cdot \mathrm{L}_{\mathrm{m}}}{\mathrm{L}_{\text {sta }}}$ 
Where $\mathrm{g}$ is the slip of the generator.

From Eqs. (17)-(18), the rotor currents expressions are deduced as follows:

$$
\begin{aligned}
& \mathrm{i}_{\text {rot_d }}=\left[\mathrm{V}_{\text {rot_d }}+\mathrm{g} \cdot \omega_{\mathrm{g}}\left(\mathrm{L}_{\text {rot }}-\frac{\mathrm{L}_{\mathrm{m}}{ }^{2}}{\mathrm{~L}_{\text {sta }}}\right) \mathrm{i}_{\text {rot } \_\mathrm{q}}\right] /\left[\mathrm{R}_{\text {rot }}+\left(\mathrm{L}_{\text {rot }}-\frac{\mathrm{L}_{\mathrm{m}}{ }^{2}}{\mathrm{~L}_{\text {sta }}}\right) \cdot \mathrm{s}\right] \\
& \mathrm{i}_{\text {rot_q }}=\left[\mathrm{V}_{\text {rot } \_\mathrm{q}}-\mathrm{g} \cdot \omega_{\mathrm{g}}\left(\mathrm{L}_{\text {rot }}-\frac{\mathrm{L}_{\mathrm{m}}{ }^{2}}{\mathrm{~L}_{\text {sta }}}\right) \mathrm{i}_{\text {rot } \_\mathrm{d}}-\mathrm{g} \frac{\mathrm{V}_{\mathrm{g}} \cdot \mathrm{L}_{\mathrm{m}}}{\mathrm{L}_{\text {sta }}}\right] /\left[\mathrm{R}_{\text {rot }}+\left(\mathrm{L}_{\text {rot }}-\frac{\mathrm{L}_{\mathrm{m}}{ }^{2}}{\mathrm{~L}_{\text {sta }}}\right) \cdot \mathrm{s}\right]
\end{aligned}
$$

The current references can be expressed as follows [7]:

$$
\begin{aligned}
& i_{\text {rot_q }}^{*}=-\frac{\mathrm{L}_{\text {sta }}}{\mathrm{L}_{\mathrm{m}} \cdot \mathrm{V}_{\mathrm{g}}} \cdot \mathrm{P}_{\mathrm{s}}^{*} \\
& \mathrm{i}_{\text {rot_d }}^{*}=-\frac{\mathrm{L}_{\text {sta }}}{\mathrm{Lm} \cdot \mathrm{V}_{\mathrm{g}}} \cdot\left(\mathrm{Q}_{\mathrm{s}}^{*}-\frac{\mathrm{V}_{\mathrm{g}}^{2}}{\omega_{\mathrm{g}} \cdot \mathrm{L}_{\text {sta }}}\right)
\end{aligned}
$$

The voltage references are expressed easily from Eqs. 17 and 18 as follows:

$$
\mathrm{V}_{\text {rot_q }}^{*}=\left[\mathrm{i}_{\text {rot_q }}^{*}-\mathrm{i}_{\text {rot_q }}\right] \cdot\left[\mathrm{K}_{\mathrm{p}-\mathrm{rscl}}+\mathrm{K}_{\mathrm{i}-\mathrm{rscl} 1} \cdot \frac{1}{\mathrm{~S}}\right]+\mathrm{e}_{\mathrm{r} \_\mathrm{d}}+\mathrm{g} \frac{\mathrm{V}_{\mathrm{g}} \cdot \mathrm{L}_{\mathrm{m}}}{\mathrm{L}_{\text {sta }}}
$$

$\mathrm{V}_{\text {rot_d }}^{*}=\left[i_{\text {rot_d }}^{*}-i_{\text {rot_d }}\right] \cdot\left[K_{p-r s c 2}+K_{i-r s c 2} \cdot \frac{1}{S}\right]+e_{r_{-} q}$

Where

$\mathrm{e}_{\mathrm{r}_{-} \mathrm{d}}=\mathrm{g} \cdot \omega_{\mathrm{g}}\left(\mathrm{L}_{\text {rot }}-\frac{\mathrm{L}_{\mathrm{m}}^{2}}{\mathrm{~L}_{\mathrm{sta}}}\right) \cdot \mathrm{i}_{\text {rot_d }}$ and $\mathrm{e}_{\mathrm{r} \_\mathrm{q}}=\mathrm{g} \cdot \omega_{\mathrm{g}}\left(\mathrm{L}_{\text {rot }}-\frac{\mathrm{L}_{\mathrm{m}}{ }^{2}}{\mathrm{~L}_{\text {sta }}}\right) \cdot \mathrm{i}_{\text {rot_q }}$

\section{Determination of the Gains of PI Controller}

To set the PI parameters $\left(\mathrm{K}_{\mathrm{p}-\mathrm{rsc}}, \mathrm{K}_{\mathrm{i}-\mathrm{rsc}}\right)$, the pole compensation method is utilized. The time constant of the system is:

$\mathrm{T}_{\mathrm{s}}=\left(\mathrm{L}_{\mathrm{rot}}-\frac{\mathrm{L}_{\mathrm{m}}^{2}}{\mathrm{~L}_{\mathrm{sta}}}\right) / \mathrm{R}_{\mathrm{rot}}$

The equations of PI parameters $\left(\mathrm{K}_{\mathrm{p}-\mathrm{rsc}}, \mathrm{K}_{\mathrm{i}-\mathrm{rsc}}\right)$ are given as follows:

$\mathrm{K}_{\mathrm{p} \_ \text {rsc }}=\frac{1}{\mathrm{~T}_{\mathrm{rsc}}} \cdot\left(\mathrm{L}_{\mathrm{rot}}-\frac{\mathrm{L}_{\mathrm{m}}^{2}}{\mathrm{~L}_{\mathrm{sta}}}\right)$ And $\mathrm{K}_{\mathrm{i}-\mathrm{rsc}}=\frac{\mathrm{K}_{\mathrm{p} \_ \text {rsc }} \cdot \mathrm{R}_{\mathrm{rot}}}{\left(\mathrm{L}_{\mathrm{rot}}-\frac{\mathrm{L}_{\mathrm{m}}^{2}}{\mathrm{~L}_{\mathrm{sta}}}\right)}$ With $\mathrm{T}_{\mathrm{rsc}}=\frac{\mathrm{T}_{\mathrm{s}}}{100}$

\section{Control of the Grid Side Converter (GSC)}

The GSC consists of controlling DC-link voltage and reactive power exchanged with the grid. To elaborate the control scheme of the GSC, the grid voltage is considered orientated to the q-axis and is determined by using the Park transformation. The Phase-Locked Loop (PLL) technique is used to obtain the angle of transformation. The grid voltages can be expressed as:

$\mathrm{V}_{\mathrm{gd}}=0$ And $\mathrm{V}_{\mathrm{gq}}=\mathrm{V}_{\mathrm{g}}$

The voltages and powers can be simplified as follows [28]:

$\mathrm{V}_{\mathrm{GSC}_{-} \mathrm{d}}=-\left[\mathrm{R}_{\mathrm{f}}+\mathrm{L}_{\mathrm{f}} \cdot \mathrm{s}\right] \cdot \mathrm{i}_{\mathrm{GSC} \_\mathrm{d}}+\omega_{\mathrm{g}} \cdot \mathrm{L}_{\mathrm{f}} \cdot \mathrm{i}_{\mathrm{GSC} \_\mathrm{q}}$

$\mathrm{V}_{\mathrm{GSC} \_\mathrm{q}}=-\left[\mathrm{R}_{\mathrm{f}}+\mathrm{L}_{\mathrm{f}} \cdot \mathrm{s}\right] \cdot \mathrm{i}_{\mathrm{GSC}_{-} \mathrm{q}}-\omega_{\mathrm{g}} \cdot \mathrm{L}_{\mathrm{f}} \cdot \mathrm{i}_{\mathrm{GSC}_{-} \mathrm{d}}+\mathrm{V}_{\mathrm{g}}$

$\mathrm{P}_{\mathrm{g}}=\mathrm{V}_{\mathrm{g}} \cdot \mathrm{i}_{\mathrm{GSC}} \mathrm{q}$

$\mathrm{Q}_{\mathrm{g}}=\mathrm{V}_{\mathrm{g}} \cdot \mathrm{i}_{\mathrm{GSC} \_\mathrm{d}}$

The relation between the powers of converters can be expressed as follows [29]:

$\mathrm{V}_{\mathrm{dC}} \cdot \mathrm{i}_{\mathrm{C}}=\mathrm{P}_{\mathrm{GSC}}-\mathrm{P}_{\mathrm{RSC}}$

The grid side converter power can be deducted as follows:

$\mathrm{P}_{\mathrm{g}}=\mathrm{P}_{\mathrm{GSC}}=\mathrm{V}_{\mathrm{dC}} \cdot \mathrm{i}_{\mathrm{C}}+\mathrm{P}_{\mathrm{RSC}}$

Where $\mathrm{P}_{\mathrm{RSC}}$ is the rotor side converter power, which can be defined as:

$\mathrm{P}_{\mathrm{RSC}}=\mathrm{V}_{\mathrm{DC}} \cdot \mathrm{i}_{\mathrm{RSC}}$

So, the DC-link power $\left(\mathrm{P}_{\mathrm{dc}}^{*}\right)$ can be expressed as:

$\mathrm{P}_{\mathrm{dc}}^{*}=\mathrm{V}_{\mathrm{DC}} \cdot \mathrm{i}_{\mathrm{c}}^{*}$

From Eqs. (31), (32), (33), (34) the references of the grid currents can be derived as follows [29]:

$i_{\text {GSC_q }}^{*}=\frac{1}{V_{g}} \cdot\left(V_{D C}^{*} \cdot i_{c}^{*}+P_{\text {RSC }}\right) ; i_{G_{\text {SSC }} d}^{*}=\frac{Q_{g}^{*}}{V_{g}}$

In order to have a unit power factor, it is supposed that the reference of reactive power is null. Therefore, we impose a null direct current grid reference $\left(i_{\mathrm{GSC} d}^{*}=0\right)$. The voltage references are expressed as follows [28]:

$\mathrm{V}_{\mathrm{gd}}^{*}=\left[\mathrm{i}_{\mathrm{GSC} \_\mathrm{d}}^{*}-\mathrm{i}_{\mathrm{GSC} \_\mathrm{d}}\right] \cdot\left[\mathrm{K}_{\mathrm{p}-\mathrm{gsc} 2}+\mathrm{K}_{\mathrm{i}-\mathrm{gsc} 2} \cdot \frac{1}{\mathrm{~S}}\right]+\mathrm{e}_{\mathrm{GSC} \_\mathrm{q}}$

$\mathrm{V}_{\mathrm{gq}}^{*}=\left[\mathrm{i}_{\mathrm{GSC} \_\mathrm{q}}^{*}-\mathrm{i}_{\mathrm{GSC} \_\mathrm{q}}\right] \cdot\left[\mathrm{K}_{\mathrm{p}-\mathrm{gsc} 1}+\mathrm{K}_{\mathrm{i}-\mathrm{gsc} 1} \cdot \frac{1}{\mathrm{~S}}\right]-\mathrm{e}_{\mathrm{GSC} \_\mathrm{d}}+\mathrm{V}_{\mathrm{g}}$

Where

$\mathrm{e}_{\mathrm{GSC}-\mathrm{q}}=\omega_{\mathrm{g}} \cdot \mathrm{L}_{\mathrm{f}} \cdot \mathrm{i}_{\mathrm{GSC} \_\mathrm{q}} ; \mathrm{e}_{\mathrm{GSC} \_\mathrm{d}}=\omega_{\mathrm{g}} \cdot \mathrm{L}_{\mathrm{f}} \cdot \mathrm{i}_{\mathrm{GSC} \_\mathrm{d}}$ 
The expressions of the grid currents can be deduced as follows [30]:

$\mathrm{i}_{\mathrm{GSC} \_\mathrm{q}}=\frac{1}{\left[\mathrm{R}_{\mathrm{f}}+\mathrm{L}_{\mathrm{f}} \cdot \mathrm{s}\right]} \cdot\left(\mathrm{V}_{\mathrm{gq}}^{*}-\omega_{\mathrm{g}} \cdot \mathrm{L}_{\mathrm{f}} \cdot \mathrm{i}_{\mathrm{GSC} \_\mathrm{d}}-\mathrm{V}_{\mathrm{DC}} \cdot \mathrm{S}_{\mathrm{q}}\right)$

$\mathrm{i}_{\mathrm{GSC} \_\mathrm{d}}=\frac{1}{\left[\mathrm{R}_{\mathrm{f}}+\mathrm{L}_{\mathrm{f}} \cdot \mathrm{s}\right]} \cdot\left(\mathrm{V}_{\mathrm{gd}}^{*}+\omega_{\mathrm{g}} \cdot \mathrm{L}_{\mathrm{f}} \cdot \mathrm{i}_{\mathrm{GSC} \_\mathrm{q}}-\mathrm{V}_{\mathrm{DC}} \cdot \mathrm{S}_{\mathrm{d}}\right)$

Where $\mathrm{S}_{\mathrm{d}}$ and $\mathrm{S}_{\mathrm{q}}$ are the switching states computed by Park transformation. The $\mathrm{PI}_{\mathrm{DC}}$ controller is employed to regulate the DC-link voltage at its reference. Therefore, The PI controller parameters are given below:

$\mathrm{K}_{\mathrm{p}-\mathrm{DC}}=2 . z \cdot \omega \cdot \mathrm{c}$ And $\mathrm{K}_{\mathrm{i}-\mathrm{DC}}=\omega^{2} . \mathrm{c}$;

Where $\mathrm{z}$ is the damping coefficient

The currents $i_{\text {gsc_q }}$ and $i_{\text {gsc } \_d}$, flowing through the RL filter, are regulated by a $\mathrm{PI}_{\mathrm{GSC}}$ controller used in the inner loop. Considering the time constant $\mathrm{T}_{\mathrm{gsc}}$ of the controlled system, the PI controller gains are:

$\mathrm{K}_{\mathrm{p}-\mathrm{gsc} 1,2}=\frac{\mathrm{L}_{\mathrm{f}}}{\mathrm{T}_{\mathrm{gsc}}} ; \mathrm{K}_{\mathrm{i}-\mathrm{gsc} 1,2}=\frac{\mathrm{R}_{\mathrm{f}}}{\mathrm{T}_{\mathrm{gsc}}}$

\section{Integral Backstepping Control}

\section{Principle of Backstepping Control}

Backstepping is a nonlinear technique capable to break a complex system down to a sequence of sub-problems on lower-order systems. The basic idea of this approach is to design a controller for a system recursively by considering some of the state variables as "Virtual Controls" and designing for them intermediate control laws with the Control Lyapunov Function (CLF) [31]. Starting by definition of a virtual control state, then, forcing it to become a stabilizing function. Consequently, by appropriately designing the related control input based on the Lyapunov stability theory, the error variable can be stabilized [32]. The integral Backstepping is a modified variant of the Backstepping control with mathematical integral action. This technique has the advantage of the ability of error cancellation in the presence of perturbation.

\section{Application of the Integral Backstepping for Controlling the MPT}

According to the equation of the dynamic rotation speed of the DFI generator given by Eq. (5), the Backstepping approach is used to develop the control, permitting the system to follow the speed corresponding to the maximum power $\left(\Omega_{\text {mec }}^{*}\right)$ [24]. Thus, the error variable is defined, in the first step, as follows:
$\epsilon_{\Omega}=\Omega_{\mathrm{mec}}^{*}-\Omega_{\mathrm{mec}}$

Using Eq. (5), the derivative of DFI generator rotation speed is defined as:

$\frac{\mathrm{d} \Omega_{\mathrm{mec}}}{\mathrm{dt}}=\frac{1}{\mathrm{~J}_{\mathrm{tot}}} \cdot\left(\mathrm{T}_{\mathrm{g}}-\mathrm{T}_{\mathrm{em}}-\mathrm{f} . \Omega_{\mathrm{mec}}\right)$

The derivative of the error presented by Eq. (45) is:

$\dot{\epsilon}_{\Omega}=\dot{\Omega}_{\text {mec }}^{*}-\dot{\Omega}_{\text {mec }}$

By replacing Eq. (46) in Eq. (47), we obtain:

$\dot{\epsilon}_{\Omega}=\dot{\Omega}_{\mathrm{mec}}-\frac{1}{\mathrm{~J}_{\mathrm{tot}}} \cdot\left(\mathrm{T}_{\mathrm{g}}-\mathrm{T}_{\mathrm{em}}-\mathrm{f} . \Omega_{\mathrm{mec}}\right)$

Choosing $\mathrm{L}_{\mathrm{f}}$ as a Lyapunov function $[26,33]$ :

$\mathrm{L}_{\mathrm{f}-\mathrm{MPPT}}=\frac{1}{2} \epsilon_{\Omega}^{2}+\frac{\alpha_{\Omega}^{2}}{2}$

Where $\alpha_{\Omega}=\mathrm{C}_{\Omega}^{\prime} \int_{0}^{\mathrm{t}} \epsilon_{\mathrm{dc}} \cdot \mathrm{d}(\mathrm{t}), \mathrm{C}_{\Omega}^{\prime}$ represents the integral action design parameter

Computing the derivative of $\mathrm{L}_{\mathrm{f}}$ as:

$\dot{\mathrm{L}}_{\mathrm{f}-\mathrm{MPPT}}=\epsilon_{\Omega} \cdot \dot{\epsilon}_{\Omega}+\alpha_{\Omega} \cdot \mathrm{C}_{\Omega}^{\prime} \cdot \epsilon_{\Omega}=\epsilon_{\Omega} \cdot\left(\dot{\Omega}_{\mathrm{mec}}^{*}-\dot{\Omega}_{\mathrm{mec}}+\mathrm{C}_{\Omega}^{\prime} \cdot \alpha_{\Omega}\right)$

Equation (50) can be written as:

$\dot{\mathrm{L}}_{\mathrm{f}-\mathrm{MPPT}}=\epsilon_{\Omega} \cdot\left[\dot{\Omega}_{\mathrm{mec}}^{*}-\frac{1}{\mathrm{~J}_{\mathrm{tot}}} \cdot\left(\mathrm{T}_{\mathrm{g}}-\mathrm{T}_{\mathrm{em}}-\mathrm{f} \cdot \Omega_{\mathrm{mec}}+\mathrm{C}_{\Omega}^{\prime} \cdot \alpha_{\Omega}\right)\right]$

To analyze the stability of this system, we define the Stabilizing function of Lyapunov, which is called virtual control as [32]:

$\dot{\mathrm{L}}_{\mathrm{f}-\mathrm{MPPT}}=-\mathrm{C}_{\mathrm{MPPT}} \cdot \epsilon_{\Omega}^{2}$

Where $\mathrm{C}_{\mathrm{MPPT}}$ is a positive constant. From Eqs. (50) and (51) we can deduce the following expression:

$\dot{\Omega}_{\mathrm{mec}}^{*}-\frac{1}{\mathrm{~J}_{\mathrm{tot}}} \cdot\left(\mathrm{T}_{\mathrm{g}}-\mathrm{T}_{\mathrm{em}}-\mathrm{f} \cdot \Omega_{\mathrm{mec}}+\mathrm{C}_{\Omega}^{\prime} \cdot \alpha_{\Omega}\right)=-\mathrm{C}_{\mathrm{MPPT}} \cdot \epsilon_{\Omega}$

From Eq. 53, the virtual command $\mathrm{T}_{\mathrm{em}}$ can be defined by: $\mathrm{T}_{\mathrm{em}}^{*}=-\mathrm{J}_{\mathrm{tot}}\left(\dot{\Omega}_{\mathrm{mec}}^{*}+\mathrm{C}_{\mathrm{MPPT}} \cdot \epsilon_{\Omega}\right)+\mathrm{T}_{\mathrm{g}}-\mathrm{f} \cdot \Omega_{\mathrm{mec}}+\mathrm{C}_{\Omega}^{\prime} \cdot \alpha_{\Omega}$

\section{Application of the Integral Backstepping for Controlling the Rotor Side Converter (RSC)}

\section{Stator Power Signals}

The RSC is designed, in this section, by Backstepping procedure to pilot the stator active and reactive power. For this 
task, virtual control should be designed based on the rotor currents. As you can see in Eqs. (21) and (22), the active power is controlled by the $i_{\text {rot_q }}$ current. However, the reactive power is piloted by the $i_{\text {rot_d }}$ current. Considering the Eqs. (17) and (18), the temporal derivation of the rotor currents equations can be deduced as follows [34]:

$\left\{\begin{array}{c}\frac{\mathrm{di}_{\text {rot_d }}}{\mathrm{dt}}=\frac{1}{\mathrm{a}}\left(\mathrm{V}_{\text {rot_d }}-\mathrm{R}_{\text {rot }} \mathrm{i}_{\text {rot_d }}+b \cdot \mathrm{i}_{\text {rot_q }}\right) \\ \frac{\mathrm{dirot \_ q}_{\mathrm{rot}}}{\mathrm{dt}}=\frac{1}{\mathrm{a}}\left(\mathrm{V}_{\text {rot_q }}-\mathrm{R}_{\text {rot }} \mathrm{i}_{\text {rot_q }}-b \cdot \mathrm{i}_{\text {rot_d }}-c\right)\end{array}\right.$

Where.

$\mathrm{a}=\mathrm{L}_{\text {rot }} \cdot\left(1-\frac{\mathrm{L}_{\mathrm{m}}^{2}}{\mathrm{~L}_{\mathrm{rot}} \cdot \mathrm{L}_{\mathrm{sta}}}\right) ; \mathrm{b}=\mathrm{g} \cdot \omega_{\mathrm{g}} \cdot \mathrm{L}_{\mathrm{rot}}\left(1-\frac{\mathrm{L}_{\mathrm{m}}^{2}}{\mathrm{~L}_{\mathrm{rot}} \cdot \mathrm{L}_{\mathrm{sta}}}\right) ; \mathrm{c}=\frac{\mathrm{L}_{\mathrm{m}} \cdot \mathrm{V}_{\mathrm{g}} \cdot \mathrm{g}}{\mathrm{L}_{\mathrm{sta}}}$

Calculating the errors between desired (reference) rotor currents and the actual one to stabilize it by Backstepping in the first step as:

$\epsilon_{\mathrm{RSC}-1}=\mathrm{i}_{\text {rot_q }}^{*}-\mathrm{i}_{\text {rot_q }}$

$\epsilon_{\text {RSC-2 }}=i_{\text {rot_d }}^{*}-i_{\text {rot_d }}$

The time derivative of the errors is given by:

$\frac{\mathrm{d}_{\mathrm{RSC}-1}}{\mathrm{dt}}=\frac{\mathrm{di}_{\text {rot_q }}^{*}}{\mathrm{dt}}-\frac{\mathrm{di}_{\text {rot_q }}}{\mathrm{dt}}$

$\frac{\mathrm{d \epsilon}_{\mathrm{RSC}-2}}{\mathrm{dt}}=\frac{\mathrm{di}_{\text {rot_d }}^{*}}{\mathrm{dt}}-\frac{\mathrm{di}_{\text {rot_d }}}{\mathrm{dt}}$

So, by replacing the time derivative of currents in Eqs. 59 and 60 , we obtain:

$\frac{\mathrm{d}_{\mathrm{RSC}-1}}{\mathrm{dt}}=\frac{\mathrm{di}_{\mathrm{rot} \_\mathrm{q}}^{*}}{\mathrm{dt}}-\frac{1}{\mathrm{a}}\left(\mathrm{V}_{\text {rot }_{\mathrm{q}}}-\mathrm{R}_{\text {rot }} \cdot \mathrm{i}_{\text {rot_q }}-\mathrm{b} \cdot \mathrm{i}_{\text {rot_d }}-\mathrm{c}\right)$

$\frac{\mathrm{d} \epsilon_{\mathrm{RSC}-2}}{\mathrm{dt}}=\frac{\mathrm{di}_{\text {rot_d }}^{*}}{\mathrm{dt}}-\frac{1}{\mathrm{a}}\left(\mathrm{V}_{\text {rot_d }}-\mathrm{R} \mathrm{i}_{\text {rot }} \mathrm{i}_{\text {rot_d }}+\mathrm{b} \cdot \mathrm{i}_{\text {rot_q }}\right)$

The Lyapunov candidate function is defined, in a second step, as follows [34, 35]:

$\mathrm{L}_{\mathrm{f}-\mathrm{r} 1}=\frac{\epsilon_{\mathrm{RSC}-1}^{2}}{2}+\frac{\alpha_{\mathrm{r} 1}^{2}}{2}$ And $\mathrm{L}_{\mathrm{f}-\mathrm{r} 2}=\frac{\epsilon_{\mathrm{RSC}-2}^{2}}{2}+\frac{\alpha_{\mathrm{r} 2}^{2}}{2}$

Where $\alpha_{\mathrm{r} 1}=\mathrm{C}_{\mathrm{r} 1}^{\prime} \int_{0}^{\mathrm{t}} \epsilon_{\mathrm{RSC}-1} \cdot \mathrm{d}(\mathrm{t})$ and $\alpha_{\mathrm{r} 2}=\mathrm{C}_{\mathrm{r} 2}^{\prime} \cdot \int_{0}^{\mathrm{t}} \epsilon_{\mathrm{RSC}-2} \cdot \mathrm{d}(\mathrm{t})$, $\mathrm{C}_{\mathrm{r} 1}^{\prime}$ and $\mathrm{C}_{\mathrm{r} 2}^{\prime}$ are the integral action invariants. The derivation of Lyapunov function is expressed as:

$\dot{\mathrm{L}}_{\mathrm{f}-\mathrm{r} 1}=\epsilon_{\mathrm{RSC}-1} \cdot \dot{\epsilon}_{\mathrm{RSC}-1}+\alpha_{\mathrm{r} 1} \cdot \mathrm{C}_{\mathrm{r} 1}^{\prime} \cdot \epsilon_{\mathrm{RSC}-1}=\epsilon_{\mathrm{RSC}-1}\left(\dot{\epsilon}_{\mathrm{RSC}-1}+\alpha_{\mathrm{r} 1} \cdot \mathrm{C}_{\mathrm{r} 1}^{\prime}\right)$

$\dot{\mathrm{L}}_{\mathrm{f}-\mathrm{r} 2}=\epsilon_{\mathrm{RSC}-2} \cdot \dot{\mathrm{e}}_{\mathrm{RSC}-2}+\alpha_{\mathrm{r} 2} \cdot \mathrm{C}_{\mathrm{r} 2}^{\prime} \cdot \epsilon_{\mathrm{RSC}-2}=\epsilon_{\mathrm{RSC}-2}\left(\dot{\epsilon}_{\mathrm{rsc} 2}+\alpha_{\mathrm{r} 2} \cdot \mathrm{C}_{\mathrm{r} 2}^{\prime}\right)$
So, replacing the errors derivation given in Eqs. 61 and 62, the Lyapunov derivative rewrites as:

$\dot{\mathrm{L}}_{\mathrm{f}-\mathrm{r} 1}=\epsilon_{\mathrm{RSC}-1} \cdot\left[\frac{\mathrm{di}_{\text {rot_q }}^{*}}{\mathrm{dt}}-\frac{1}{\mathrm{a}}\left(\mathrm{V}_{\text {rot_q }}-\mathrm{R}_{\text {rot }} \mathrm{i}_{\text {rot_q }}-\mathrm{b} \cdot \mathrm{i}_{\text {rot_d }}-\mathrm{c}\right)+\alpha_{\mathrm{r} 1} \cdot \mathrm{C}_{\mathrm{r} 1}^{\prime}\right]$

$\dot{\mathrm{L}}_{\mathrm{f}-\mathrm{r} 2}=\epsilon_{\mathrm{RSC}-2} \cdot\left[\frac{\mathrm{di}_{\text {rot_d }}^{*}}{\mathrm{dt}}-\frac{1}{\mathrm{a}}\left(\mathrm{V}_{\text {rot_d }}-\mathrm{R}_{\text {rot }} \mathrm{i}_{\text {rot_d }}+\mathrm{b} \cdot \mathrm{i}_{\text {rot_q }}\right)+\alpha_{\mathrm{r} 2} \cdot \mathrm{C}_{\mathrm{r} 2}^{\prime}\right]$

To ensure the system stability, according to Lyapunov function, the derivation of $\mathrm{L}_{\mathrm{f}-\mathrm{rsc}}$ must be negative and is given as follows:

$\dot{\mathrm{L}}_{\mathrm{f}-\mathrm{r} 1}=-\mathrm{C}_{\mathrm{RSC}-1} \cdot \epsilon_{\mathrm{RSC}-1}^{2}$ And $\dot{\mathrm{L}}_{\mathrm{f}-\mathrm{r} 2}=-\mathrm{C}_{\mathrm{RSC}-2} \cdot \epsilon_{\mathrm{RSC}-1}^{2}$

Where $\mathrm{C}_{\mathrm{rsc} 1}$ and $\mathrm{C}_{\mathrm{rsc} 2}$ are positive constants. By equalizing the Eqs. 66 and 67 with Eq. 68, we obtain:

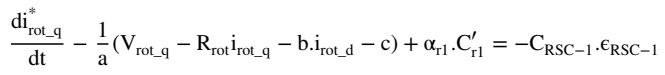

$\frac{\mathrm{di}_{\text {rot_d d }}^{*}}{\mathrm{dt}}-\frac{1}{\mathrm{a}}\left(\mathrm{V}_{\text {rot_d }}-\mathrm{R}_{\text {rot }} \mathrm{i}_{\text {rot_d }}+\mathrm{b} \cdot \mathrm{i}_{\text {rot_ } \mathrm{q}}\right)+\alpha_{\mathrm{r} 2} \cdot \mathrm{C}_{\mathrm{r} 2}^{\prime}=-\mathrm{C}_{\mathrm{RSC}-2} \cdot \mathrm{C}_{\mathrm{RSC}-2}$

Therefore, the virtual command $\mathrm{V}_{\mathrm{rd}}$ and $\mathrm{V}_{\mathrm{rq}}$ are deduced directly as follows:

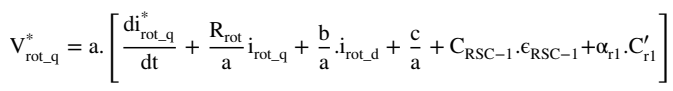

$\mathrm{V}_{\text {rot_d }}^{*}=\mathrm{a} \cdot\left[\frac{\mathrm{di}_{\text {rot_d }}^{*}}{\mathrm{dt}}+\frac{\mathrm{R}_{\text {rot }}}{\mathrm{a}} \mathrm{i}_{\text {rot_d }}-\frac{\mathrm{b}}{\mathrm{a}} \cdot \mathrm{i}_{\text {rot_q }}+\mathrm{C}_{\mathrm{RSC}-2} \cdot \mathrm{\epsilon}_{\mathrm{RSC}-2}+\alpha_{\mathrm{rl} 1} \cdot \mathrm{C}_{\mathrm{r} 1}^{\prime}\right]$

\section{Application of the Integral Backstepping for Controlling the DC-link Voltage and the GSC}

\section{DC control Signal}

Let us determine the derivative error $\epsilon_{\mathrm{dc}}$ between the DClink voltage and its desired [35]:

$\dot{\mathrm{e}}_{\mathrm{dc}}=\dot{\mathrm{V}}_{\mathrm{dc}}^{*}-\dot{\mathrm{V}}_{\mathrm{dc}}$, with $\dot{\mathrm{V}}_{\mathrm{dc}}=\frac{\mathrm{i}_{\mathrm{c}}}{\mathrm{C}}$

Selecting the first Lyapunov function associated with the DC bus voltage error with the error integral action value [34, 35]:

$\mathrm{L}_{\mathrm{f}-\mathrm{dc}}=\frac{\epsilon_{\mathrm{dc}}^{2}}{2}+\frac{\alpha_{\mathrm{dc}}^{2}}{2}$

Where $\alpha_{\mathrm{dc}}=\mathrm{C}_{\mathrm{dc}}^{\prime} \int_{0}^{\mathrm{t}} \epsilon_{\mathrm{dc}} \cdot \mathrm{d}(\mathrm{t}) . \mathrm{C}_{\mathrm{dc}}{ }_{\mathrm{dc}}$ represents the integral action invariant. 
The derivative of Eq. 74 applies:

$\dot{\mathrm{L}}_{\mathrm{f}-\mathrm{dc}}=\epsilon_{\mathrm{dc}} \cdot \dot{\epsilon}_{\mathrm{dc}}+\alpha_{\mathrm{dc}} \cdot \mathrm{C}_{\mathrm{dc}}^{\prime} \cdot \epsilon_{\mathrm{dc}}=\epsilon_{\mathrm{dc}}\left(\dot{\mathrm{V}}_{\mathrm{dc}}^{*}-\frac{\dot{\mathrm{i}}_{\mathrm{c}}}{\mathrm{C}}+\alpha_{\mathrm{dc}} \cdot \mathrm{C}_{\mathrm{dc}}^{\prime}\right)$

This can be rewritten satisfying $\dot{\mathrm{L}}_{\mathrm{f}-\mathrm{dc}}<0$ as follows:

$\dot{\mathrm{L}}_{\mathrm{f}-\mathrm{dc}}=-\mathrm{C}_{\mathrm{dc}} \cdot \epsilon_{\mathrm{dc}}^{2}$

Where $\mathrm{C}_{\mathrm{dc}}$ is a positive parameter. Considering Eqs. 74 and 76 , we can write:

$\dot{\mathrm{V}}_{\mathrm{dc}}^{*}-\frac{\mathrm{i}_{\mathrm{c}}}{\mathrm{C}}+\alpha_{\mathrm{dc}} \cdot \mathrm{C}_{\mathrm{dc}}^{\prime}=-\mathrm{C}_{\mathrm{dc}} \cdot \epsilon_{\mathrm{dc}}$

Equation 77 allows the synthesis of the DC link current reference $\left(\mathrm{i}_{\mathrm{c}}^{*}\right)$ such as:

$\mathrm{i}_{\mathrm{c}}^{*}=\mathrm{C} \cdot\left(\dot{\mathrm{V}}_{\mathrm{dc}}^{*}+\mathrm{C}_{\mathrm{dc}} \cdot \epsilon_{\mathrm{dc}}+\alpha_{\mathrm{dc}} \cdot \mathrm{C}_{\mathrm{dc}}^{\prime}\right)$

On the other hand, we have:

$i_{c}^{*}=\frac{P_{d c}^{*}}{V_{d c}}$

$\mathrm{P}_{\mathrm{dc}}^{*}=\mathrm{P}_{\mathrm{gsc}}^{*}-\mathrm{P}_{\mathrm{rsc}}$

$i_{\mathrm{gq}}^{*}=\frac{\mathrm{P}_{\mathrm{gsc}}^{*}}{\mathrm{~V}_{\mathrm{g}}}$

Therefore, the quadrature grid current reference can be expressed as a function of the DC-link voltage as:

$\mathrm{i}_{\mathrm{gq}}^{*}=\frac{\mathrm{C} \cdot \mathrm{V}_{\mathrm{dc}} \cdot\left(\dot{\mathrm{V}}_{\mathrm{dc}}^{*}+\mathrm{C}_{\mathrm{dc}} \cdot \epsilon_{\mathrm{dc}}+\alpha_{\mathrm{dc}} \cdot \mathrm{C}_{\mathrm{dc}}^{\prime}\right)+\mathrm{P}_{\mathrm{rsc}}}{\mathrm{V}_{\mathrm{g}}}$

\section{GSC Control Signals}

The expressions of the time derivative of grid currents are given in d-q frame reference as [18]:

$\frac{\mathrm{di}_{\mathrm{gq}}}{\mathrm{dt}}=\frac{1}{\mathrm{~L}_{\mathrm{f}}}\left(-\mathrm{V}_{\mathrm{gq}}-\mathrm{R}_{\mathrm{f}} \mathrm{i}_{\mathrm{gq}}-\omega_{\mathrm{g}} \cdot \mathrm{L}_{\mathrm{f}} \cdot \mathrm{i}_{\mathrm{gd}}+\mathrm{V}_{\mathrm{g}}\right)$

$\frac{\mathrm{di}_{\mathrm{gd}}}{\mathrm{dt}}=\frac{1}{\mathrm{~L}_{\mathrm{f}}}\left(-\mathrm{V}_{\mathrm{gd}}-\mathrm{R}_{\mathrm{f}} \mathrm{i}_{\mathrm{gd}}+\omega_{\mathrm{g}} \cdot \mathrm{L}_{\mathrm{f}} \cdot \mathrm{i}_{\mathrm{gq}}\right)$

The derivative of the errors of the component currents flowing through the filter $\epsilon_{\mathrm{GSC}-1}$ and $\epsilon_{\mathrm{GSC}-2}$ is defined as:
$\frac{\mathrm{d}_{\mathrm{GSC}-1}}{\mathrm{dt}}=\frac{\mathrm{di}_{\mathrm{gq}}^{*}}{\mathrm{dt}}-\frac{\mathrm{di}_{\mathrm{gq}}}{\mathrm{dt}}$

$\frac{\mathrm{d}_{\mathrm{GSC}-2}}{\mathrm{dt}}=\frac{\mathrm{di}_{\mathrm{gd}}^{*}}{\mathrm{dt}}-\frac{\mathrm{di}_{\mathrm{gd}}}{\mathrm{dt}}$

Replacing the Eqs. 83 and 84 in Eqs. 85 and 86, respectively, the errors derivative becomes:

$\frac{\mathrm{d}_{\mathrm{GSC}-1}}{\mathrm{dt}}=\frac{\mathrm{di}_{\mathrm{gq}}^{*}}{\mathrm{dt}}-\frac{1}{\mathrm{~L}_{\mathrm{f}}}\left(-\mathrm{V}_{\mathrm{gq}}-\mathrm{R}_{\mathrm{f}} \mathrm{i}_{\mathrm{gq}}-\omega_{\mathrm{g}} \cdot \mathrm{L}_{\mathrm{f}} \cdot \mathrm{i}_{\mathrm{gd}}+\mathrm{V}_{\mathrm{g}}\right)$

$\frac{\mathrm{d} \epsilon_{\mathrm{GSC}-2}}{\mathrm{dt}}=\frac{\mathrm{di}_{\mathrm{gd}}^{*}}{\mathrm{dt}}-\frac{1}{\mathrm{~L}_{\mathrm{f}}}\left(-\mathrm{V}_{\mathrm{gd}}-\mathrm{R}_{\mathrm{f}} \mathrm{i}_{\mathrm{gd}}+\omega_{\mathrm{g}} \cdot \mathrm{L}_{\mathrm{f}} \cdot \mathrm{i}_{\mathrm{gq}}\right)$

Lyapunov function is given as expression:

$\mathrm{L}_{\mathrm{f}-\mathrm{g} 1}=\frac{\epsilon_{\mathrm{GSC}-1}^{2}}{2}+\frac{\alpha_{\mathrm{g} 1}^{2}}{2}$ And $\mathrm{L}_{\mathrm{f}-\mathrm{g} 2}=\frac{\epsilon_{\mathrm{GSC}-2}^{2}}{2}+\frac{\alpha_{\mathrm{g} 2}^{2}}{2}$

Where $\alpha_{\mathrm{g} 1}=\mathrm{C}_{\mathrm{g} 1}^{\prime} \int_{0}^{\mathrm{t}} \epsilon_{\mathrm{GSC}-1} \cdot \mathrm{d}(\mathrm{t})$ and $\alpha_{\mathrm{g} 2}=\mathrm{C}_{\mathrm{g} 2}^{\prime} \cdot \int_{0}^{\mathrm{t}} \epsilon_{\mathrm{GSC}-2} \cdot \mathrm{d}(\mathrm{t})$, $\mathrm{C}_{\mathrm{g} 1}^{\prime}$ and $\mathrm{C}_{\mathrm{g} 2}^{\prime}$ are the integral action invariants. The derivation of Lyapunov function is expressed as:

$\dot{\mathrm{L}}_{\mathrm{f}-\mathrm{g} 1}=\epsilon_{\mathrm{GSC}-1} \cdot \dot{\epsilon}_{\mathrm{GSC}-1}+\alpha_{\mathrm{g} 1} \cdot \mathrm{C}_{\mathrm{g} 1}^{\prime} \cdot \epsilon_{\mathrm{GSC}-1}=\epsilon_{\mathrm{GSC}-1}\left(\dot{\epsilon}_{\mathrm{GSC}-1}+\alpha_{\mathrm{g} 1} \cdot \mathrm{C}_{\mathrm{g} 1}^{\prime}\right)$

$\dot{\mathrm{L}}_{\mathrm{f}-\mathrm{g} 2}=\epsilon_{\mathrm{GSC}-2} \cdot \dot{\epsilon}_{\mathrm{GSC}-2}+\alpha_{\mathrm{g} 2} \cdot \mathrm{C}_{\mathrm{g} 2}^{\prime} \cdot \epsilon_{\mathrm{GSC}-2}=\epsilon_{\mathrm{GSC}-2}\left(\dot{\epsilon}_{\mathrm{GSC}-2}+\alpha_{\mathrm{g} 2} \cdot \mathrm{C}_{\mathrm{g} 2}^{\prime}\right)$

In order to guarantee the stability of the system according to Lyapunov, the derivation of $\mathrm{L}_{\mathrm{f}-\mathrm{gsc}}$ must be negative:

$\dot{\mathrm{L}}_{\mathrm{f}-\mathrm{gsc}}=-\mathrm{C}_{\mathrm{gsc} 1} \cdot \epsilon_{\mathrm{GSC}-1}^{2}-\mathrm{C}_{\mathrm{gsc} 2} \cdot \epsilon_{\mathrm{GSC}-2}^{2}$

The virtual command of rotor current is deduced as:

$\frac{\mathrm{di}_{\mathrm{gq}}^{*}}{\mathrm{dt}}-\frac{1}{\mathrm{~L}_{\mathrm{f}}}\left(-\mathrm{V}_{\mathrm{gq}}-\mathrm{R}_{\mathrm{f}} \mathrm{i}_{\mathrm{gq}}-\omega_{\mathrm{g}} \cdot \mathrm{L}_{\mathrm{f}} \cdot \mathrm{i}_{\mathrm{gd}}+\mathrm{V}_{\mathrm{g}}\right)+\alpha_{\mathrm{g} 1} \cdot \mathrm{C}_{\mathrm{g} 1}^{\prime}=-\mathrm{C}_{\mathrm{gsc}} \cdot \epsilon_{\mathrm{GSC}-1}$

$\frac{\mathrm{di}_{\mathrm{gd}}^{*}}{\mathrm{dt}}-\frac{1}{\mathrm{~L}_{\mathrm{f}}}\left(-\mathrm{V}_{\mathrm{gd}}-\mathrm{R}_{\mathrm{f}} \mathrm{i}_{\mathrm{gd}}-\omega_{\mathrm{g}} \cdot \mathrm{L}_{\mathrm{f}} \cdot \mathrm{i}_{\mathrm{gq}}\right)+\alpha_{\mathrm{g} 2} \cdot \mathrm{C}_{\mathrm{g} 1}^{\prime}=-\mathrm{C}_{\mathrm{gsc} 2} \cdot \epsilon_{\mathrm{gsc}-2}$

Which gives the expression of the actual global command $\mathrm{V}_{\mathrm{gd}}$ and $\mathrm{V}_{\mathrm{gq}}$ are defined by:

$\mathrm{V}_{\mathrm{gq}}=-\mathrm{L}_{\mathrm{f}} \cdot\left[\frac{\mathrm{di}_{\mathrm{gq}}^{*}}{\mathrm{dt}}+\alpha_{\mathrm{g} 1} \cdot \mathrm{C}_{\mathrm{g} 1}^{\prime}+\mathrm{C}_{\mathrm{gsc} 1} \cdot \epsilon_{\mathrm{GSC}-1}\right]-\mathrm{R}_{\mathrm{f}} \cdot \mathrm{i}_{\mathrm{gq}}-\omega_{\mathrm{s}} \cdot \mathrm{L}_{\mathrm{f}} \cdot \mathrm{i}_{\mathrm{gd}}+\mathrm{V}_{\mathrm{g}}$

$\mathrm{V}_{\mathrm{gd}}=-\mathrm{L}_{\mathrm{f}} \cdot\left[\frac{\mathrm{di}_{\mathrm{gd}}^{*}}{\mathrm{dt}}+\alpha_{\mathrm{g} 2} \cdot \mathrm{C}_{\mathrm{g} 2}^{\prime}+\mathrm{C}_{\mathrm{gsc} 2} \cdot \epsilon_{\mathrm{GSC}-2}\right]-\mathrm{R}_{\mathrm{f}} \cdot \mathrm{i}_{\mathrm{gd}}+\omega_{s} \cdot \mathrm{L}_{\mathrm{f}} \cdot \mathrm{i}_{\mathrm{gq}}$ 
Fig. 2 Variable wind speed profile $(\mathrm{m} / \mathrm{s})$

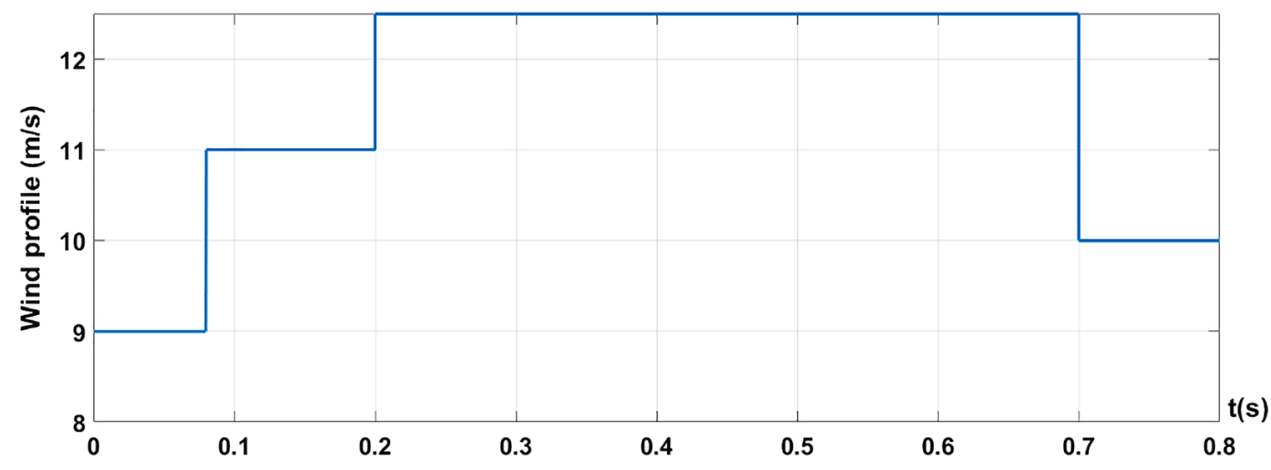

\section{Results and Discussion}

The wind power plant based on the wound rotor induction generator is modeled by diverse equations established previously and simulated employing the parameters presented in Table 1 under Matlab/Simulink software. The wind profile speed used to simulate the system is presented in Fig. 2. The superiority of the integral Backstepping is performed in normal conditions and under generator parameters variation.

\section{Dynamic Response in Normal Conditions}

This part shows the simulation results of the DFIG which is driven to rotate by the wind turbine and is connected to the non-ideal grid. The grid voltages components are computed using the Park transformation, which is based on the angle transformation obtained by the Phase-Locked Loop (PLL) with the PI controller. Figure 3 shows the quadrature and direct voltages of the grid used to feed the generator. Figure 4 presents the three-phase stator currents with a stator frequency is equal to $50 \mathrm{~Hz}$. Figure 5 presents the mechanical rotation speed, which is obtained by utilizing the MPT strategy on the basis of the PI controller, the Conventional Backstepping, and the Integral Backstepping control. The latter offers a short time for tracking the speed reference without an overshoot compared to the other techniques. However, Fig. 6 illustrates the coefficient power of the wind turbine calculated by the three methods. As you can see, the IBSC maintains the $\mathrm{C}_{\mathrm{p}}$ factor to its optimal value $\left(\mathrm{C}_{\mathrm{pmax}}=\right.$ $0.5)$, for which the tip speed ratio is optimal $\left(\lambda_{\text {opt }}=9.19\right)$, and the aerodynamic power is at its maximum value. Besides, the perturbation of the wind speed variation is rejected in court time. Figure 7 shows the stator active power computed by the studied controls. As demonstrated by comparing these results, the produced power perfectly follows the reference $\left(\mathrm{P}_{\mathrm{s}}^{*}\right)$ by utilizing the Integral Backstepping than the Conventional Backstepping and the indirect vector control, respectively, with better performances in terms of rapidity and precision. Figure 8 shows the reactive power, which is regulated to zero for ensuring a unit power factor, as shown in Fig. 9. Remarkably, the Backstepping with integral action gives better performances, and the power factor is regulated to one regardless of the variation of the wind speed profile. Figure 10 shows the influence of the wind speed variation on the DC link voltage. We can confirm that the main advantage of integral Backstepping by quickly rejecting the wind disturbance and keeping the DC-link voltage constant with a zero error. Likewise, the overshoot is considerably enhanced by using the proposed technique than conventional Backstepping and classical PI controller, respectively. Table 2 presents comparative results between the three strategies, which are calculated for the rated values. As can be seen, the IBSC reveals better results than the conventional Backstepping and indirect vector control built on the PI controller. The overshoot is eliminated, the response time is considerably reduced, and the static error is canceled by using the proposed technique.

\section{Dynamic Response Under Parameters Variation}

This section tests the robustness of the Integral Backstepping controller against unexpected variation of the generator

Table 1 The nominal values of the parameters of the studied Wind Power Plant System

\begin{tabular}{llll}
\hline & Parameters & Symbol & Values \\
\hline Turbine & Radius of blade & $\mathrm{R}$ & $51,583 \mathrm{~m}$ \\
& Coefficient of multiplier & $\mathrm{G}_{\mathrm{B}}$ & 47,23 \\
& Total moment of inertia & $\mathrm{J}_{\text {tot }}$ & $1000 \mathrm{~kg} \cdot \mathrm{m}^{2}$ \\
DFIG & DFIG rated power & Ps & $5 \mathrm{MW}$ \\
& Stator leakage inductance & Lsta & $1,2721 \mathrm{mH}$ \\
& Rotor resistance & Rrot & $1,446 \mathrm{~m} \Omega$ \\
& Rotor leakage inductance & Lrot & $1,1194 \mathrm{mH}$ \\
& Mutual inductance & Lm & $0,55187 \mathrm{mH}$ \\
& Stator line to line voltage & Vg & $950 \mathrm{~V}$ \\
Capacity & DC-link capacitance & $\mathrm{C}$ & $4400 \mu \mathrm{F}$ \\
Filter RL & Resistor of the filter & $\mathrm{R}_{\mathrm{f}}$ & $20 \Omega$ \\
& Inductance of the filter & $\mathrm{L}_{\mathrm{f}}$ & $0,08 \mathrm{H}$ \\
\hline
\end{tabular}


Fig. 3 Grid voltage components (V)

Fig. 4 Stator three-phase currents

Fig. 5 Rotational speed calculated by the MPT strategy $(\mathrm{rad} / \mathrm{s})$

Fig. 6 Power Coefficient of the wind turbine computed by the three techniques
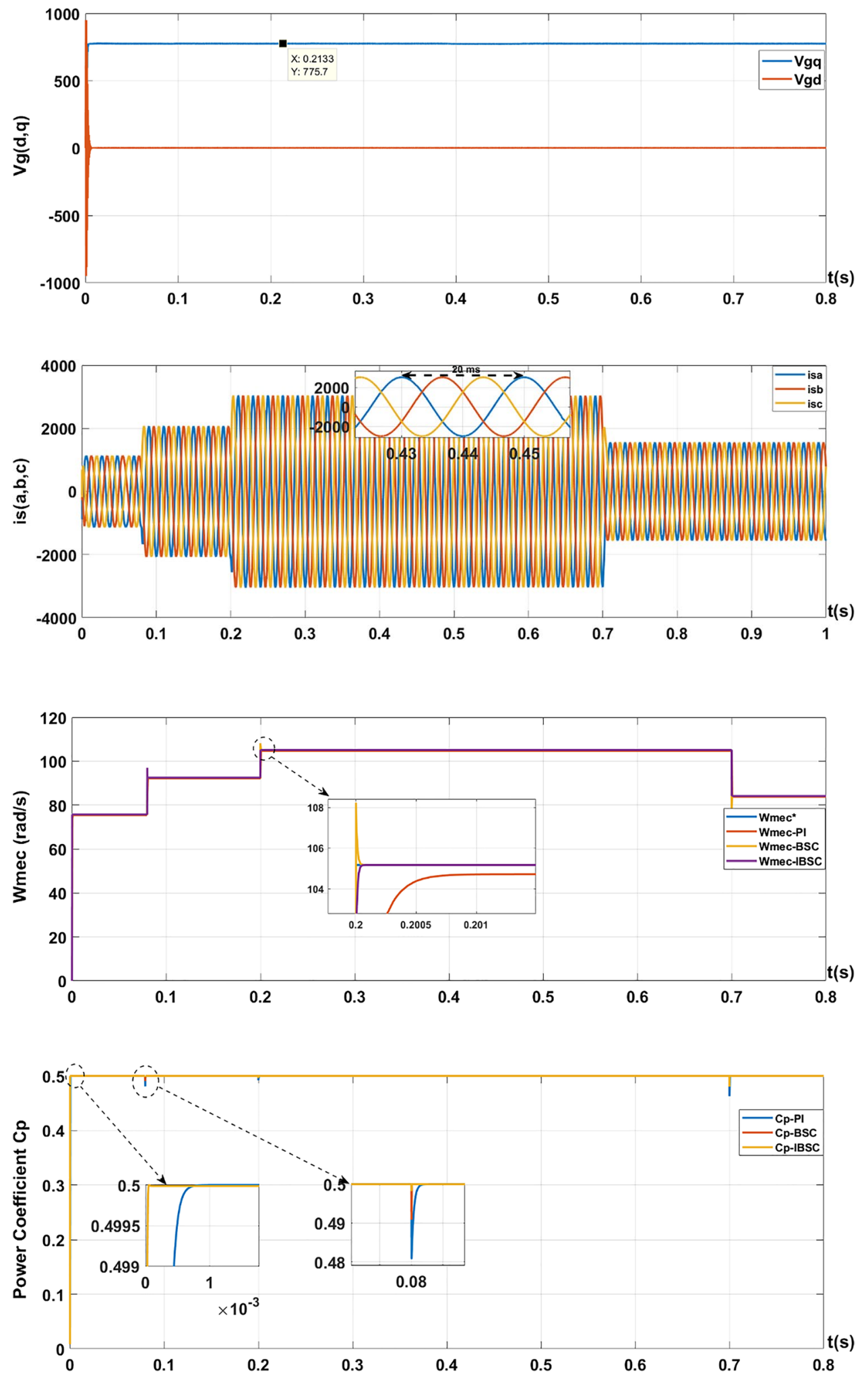

internal parameters. For this task, several cases are considered and studied.

First, the mutual inductance is increased by $+20 \%$ of its rated value. Figure 11 shows the influence of this parameter on the generated active power. As you can see, the IBSC ensures a better set-point tracking with a short response time and zero error. The mutual inductance is reduced by - $20 \%$ for more sensitivity analysis, as illustrated in Fig. 12. As you 
Fig. 7 Stator Active Power (W)

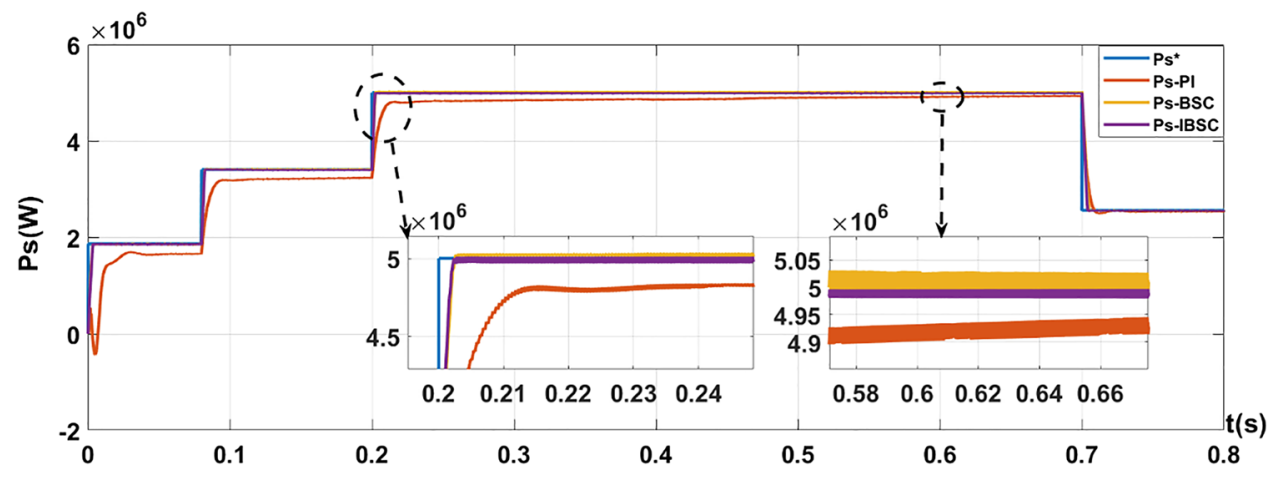

Fig. 8 Stator Reactive Power (VAR)

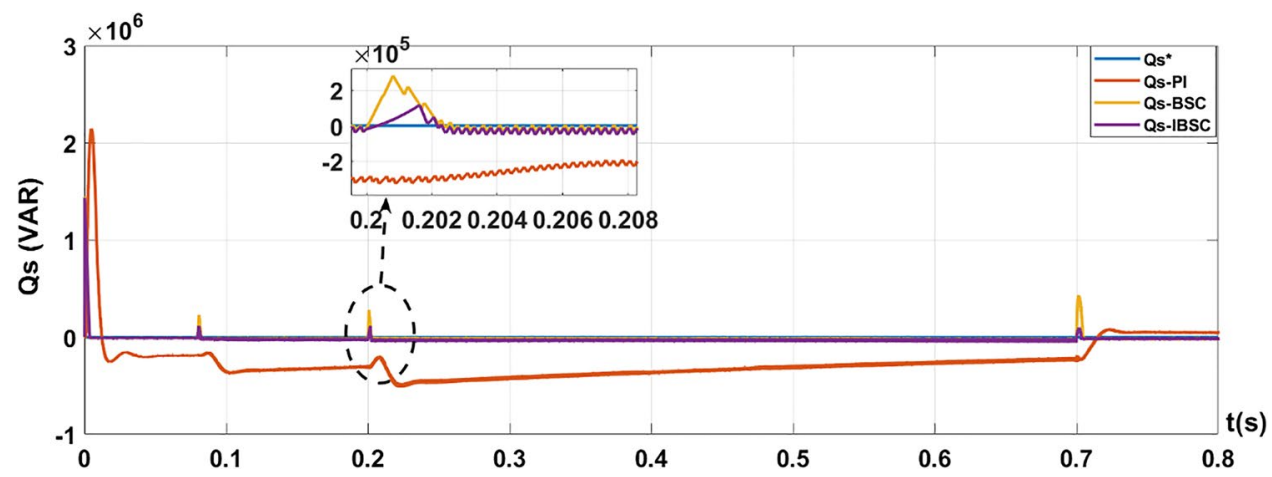

can observe, the proposed technique ensures the system's stability while avoiding static error. However, it is destroyed by using the indirect vector control.

The second case concerns the variation of the rotor resistance by $+100 \%$ (example of rotor windings warming-up, (Djeriri and DJERIRI [13]; Nadour et al. [20]). Figure 13 illustrates that the response time of the IBSC and the BSC is similar and becomes long by applying the IFAC technique. However, IBSC demonstrates a zero error.

The third situation is about increasing the rotor inductance by $+100 \%$, as shown in Fig. 14. Remarkably, the stability of the produced power is guaranteed by the IBSC and BSC. However, it is lost by using the IFAC based on the PI controller.

Fourth, the inductance and resistance of the rotor are changed simultaneously by $100 \%$. As you can see in Fig. 15, the IBSC shows better performances in terms of precision and stability than the BSC and IFAC, respectively.

And finally, the fifth state tests the influence of the stator inductance, which is increased by $+100 \%$, on the produced power. It can be observed that the IBSC affirms superiority against parameters, as shown in Fig. 16.
These results conduct us to close that the integral Backstepping control is more robust in terms of canceling the error than the Backstepping, and indirect field-aligned control.

The proposed strategy is compared to existing control approaches published in the literature as shown in Table 3. This comparison is made using the response time, the error in steady state, and the overshoot. The Integral Backstepping strategy clearly reacts faster than the other strategies, with no static error and no overshoot.

\section{Conclusions}

In this manuscript, the wind energy system is modeled, controlled, and is simulated based on a variable wind speed profile. The DFIG stator is directly linked to the electrical network, and the rotor is coupled via two bidirectional converters. First, the Maximum Power Tracking with speed regulation is designed. Second, the control of the powers is established by using Integral Backstepping Control, Conventional Backstepping, and indirect field-aligned control based on the PI controller, in which their gains are calculated by pole compensation 
Fig. 9 Unit Power Factor (UPF)

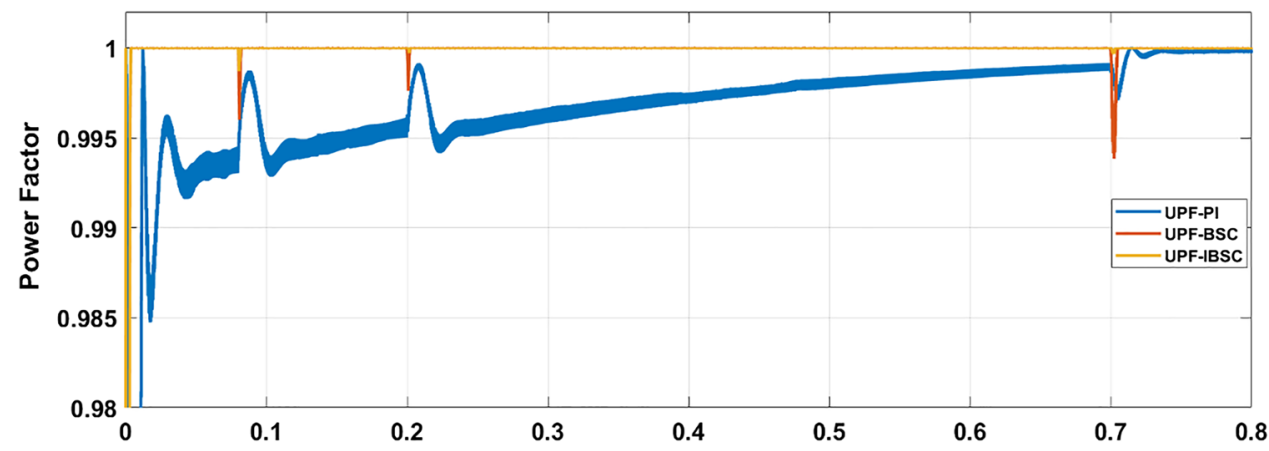

Fig. 10 DC-Link Voltage (V)

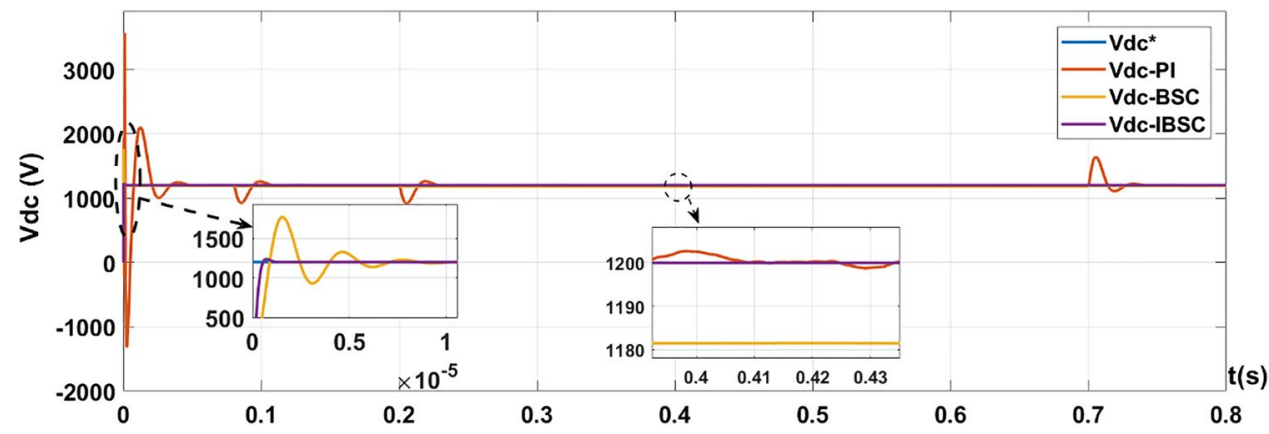

Table 2 Comparative analysis of the three methods in normal conditions

\begin{tabular}{|c|c|c|c|c|c|c|c|c|c|}
\hline \multirow[b]{2}{*}{ Performances } & \multicolumn{3}{|c|}{$\begin{array}{l}\text { Active Power } \\
\text { (rated value : } 5 \mathrm{MW} \text { ) }\end{array}$} & \multicolumn{3}{|c|}{$\begin{array}{l}\text { DC link Voltage } \\
\text { (rated value : } 1200 \mathrm{~V} \text { ) }\end{array}$} & \multicolumn{3}{|c|}{$\begin{array}{l}\text { Rotational speed } \\
\text { (rated value : } 105.2 \mathrm{rad} / \mathrm{s})\end{array}$} \\
\hline & PI & BSC & IBSC & PI & BSC & IBSC & PI & BSC & IBSC \\
\hline Response time & $10,7 \mathrm{~ms}$ & $1,7 \mathrm{~ms}$ & $1.7 \mathrm{~ms}$ & $35,3 \mathrm{~ms}$ & $7,36 \mu \mathrm{s}$ & $6,1 \mu \mathrm{s}$ & $0.1 \mathrm{~ms}$ & $50 \mu \mathrm{s}$ & $50 \mu \mathrm{s}$ \\
\hline Static error $(\%)$ & 1.34 & 0.32 & 0 & 0.25 & 1.58 & 0 & 0,5 & 0 & 0 \\
\hline Overshoot (\%) & - & - & - & 16.19 & 3.92 & 0.25 & 0 & 2.7 & 0 \\
\hline Robustness & Not robust & Medium & Robust & Not robust & Medium & Robust & Not robust & Medium & Robust \\
\hline
\end{tabular}

method. Finally, the robustness tests are done by varying all the parameters of the generator. The simulation results show that:
- The response time of the Integral and Conventional Backstepping controllers is similar in terms of power reference tracking in ideal conditions, and it is low-
Fig. 11 Stator Active Power (W) $-\mathrm{L}_{\mathrm{m}}{ }^{\prime}=\mathrm{L}_{\mathrm{m}}+20 \%$

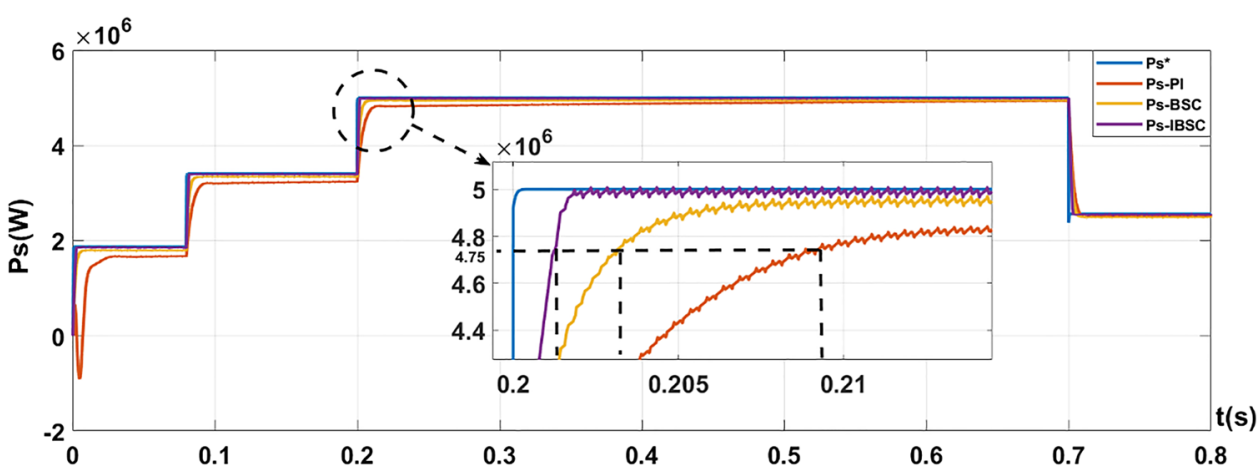


Fig. 12 Stator Active Power (W) $-\mathrm{L}_{\mathrm{m}}{ }^{\prime}=\mathrm{L}_{\mathrm{m}}-20 \%$
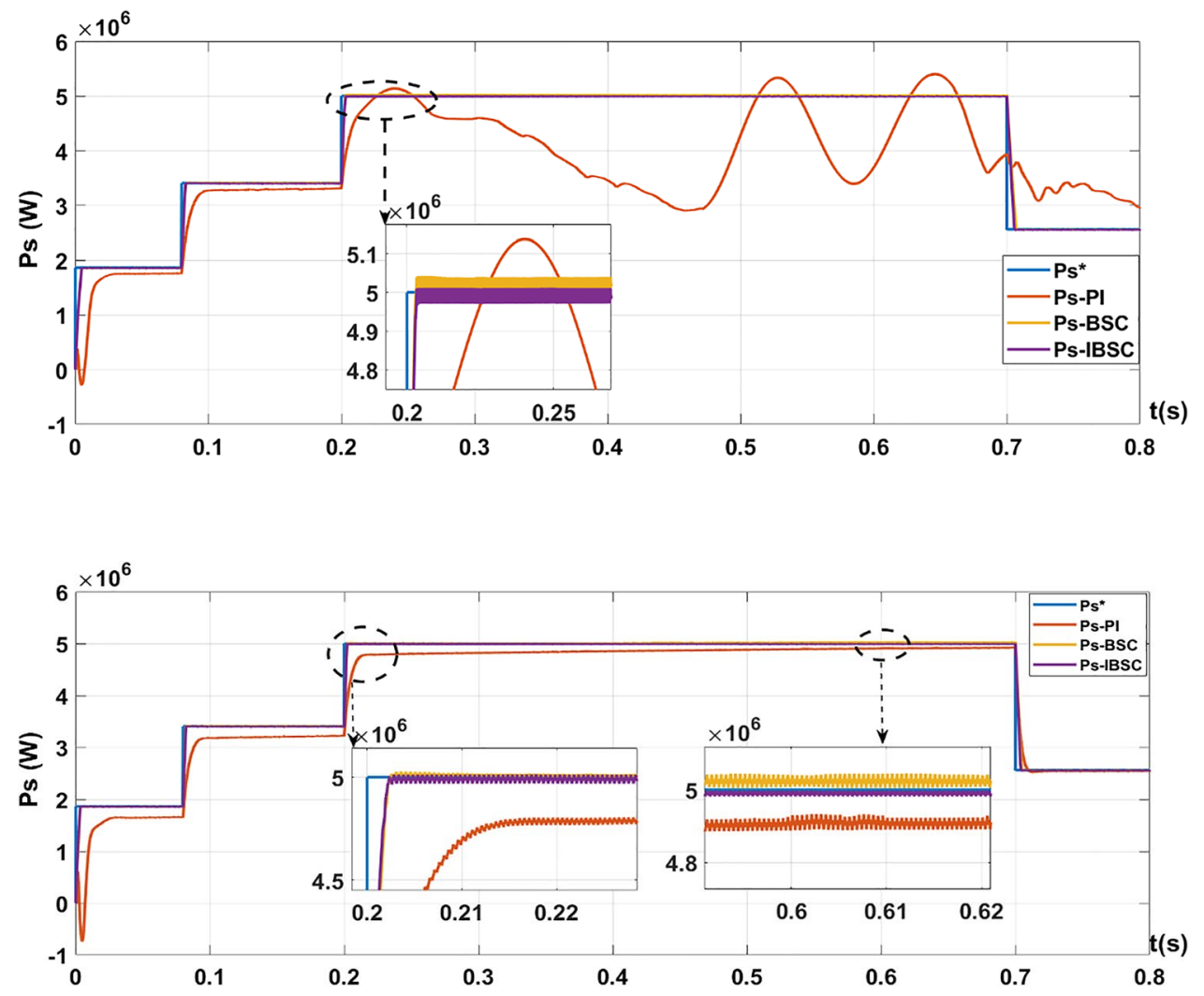

Fig. 13 Stator Active Power (W) $-\mathrm{R}_{\mathrm{rot}}{ }^{\prime}=2 \cdot \mathrm{R}_{\mathrm{rot}}$

Fig. 14 Stator active power (W) - $\mathrm{L}_{\text {rot }}{ }^{\prime}=2 \cdot \mathrm{L}_{\text {rot }}$

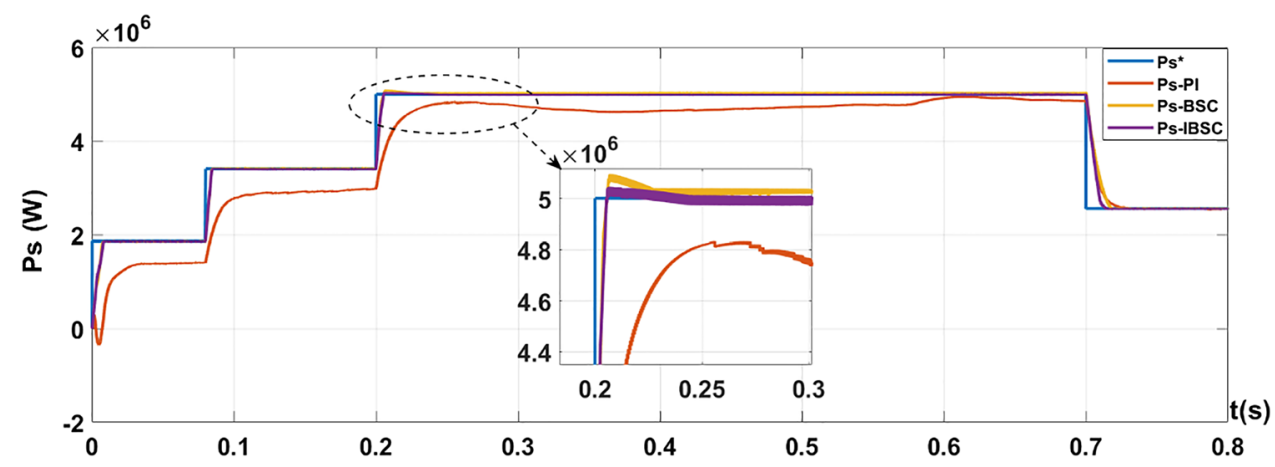

ered by $84.11 \%$ when compared to the indirect vector control. Besides, the Backstepping with integral action ensures a reference track with a null error because of the integral action.

- The performances of the Integral Backstepping are satisfactory and very attractive than the Conventional
Backstepping and the Indirect Vector Control, respectively, in terms of DC-link voltage regulation under wind speed variation. When compared to the results achieved by Conventional Backstepping and Indirect Vector Control, the response time is reduced by $17.12 \%$ and $99.97 \%$, respectively. Furthermore, when
Table 3 Comparative the proposed method with another existing methods

\begin{tabular}{llcll}
\hline Ref. Paper & Approach & $\begin{array}{l}\text { Response } \\
\text { time }(\mathrm{ms})\end{array}$ & Static error & Overshoot (\%) \\
\hline Chojaa et al. [16] & Integral Sliding Mode & 280 & $+/-0.31 \times 10^{4}$ & $\approx 5$ \\
El Moubarit et al. [18] & Nonlinear Backstepping Controller & 70 & - & $\approx 0.3$ \\
Proposed technique & Integral Backstepping Control & 1,7 & 0 & No overshoot \\
\hline
\end{tabular}


Fig. 15 Stator active power (W) - $\mathrm{L}_{\text {rot }}{ }^{\prime}=2 \cdot \mathrm{L}_{\text {rot }}$ and $\mathrm{R}_{\text {rot }}{ }^{\prime}=2 \cdot \mathrm{R}_{\text {rot }}$

Fig. 16 Stator active power (W) - $\mathrm{L}_{\text {sta }}{ }^{\prime}=2 \cdot \mathrm{L}_{\text {sta }}$
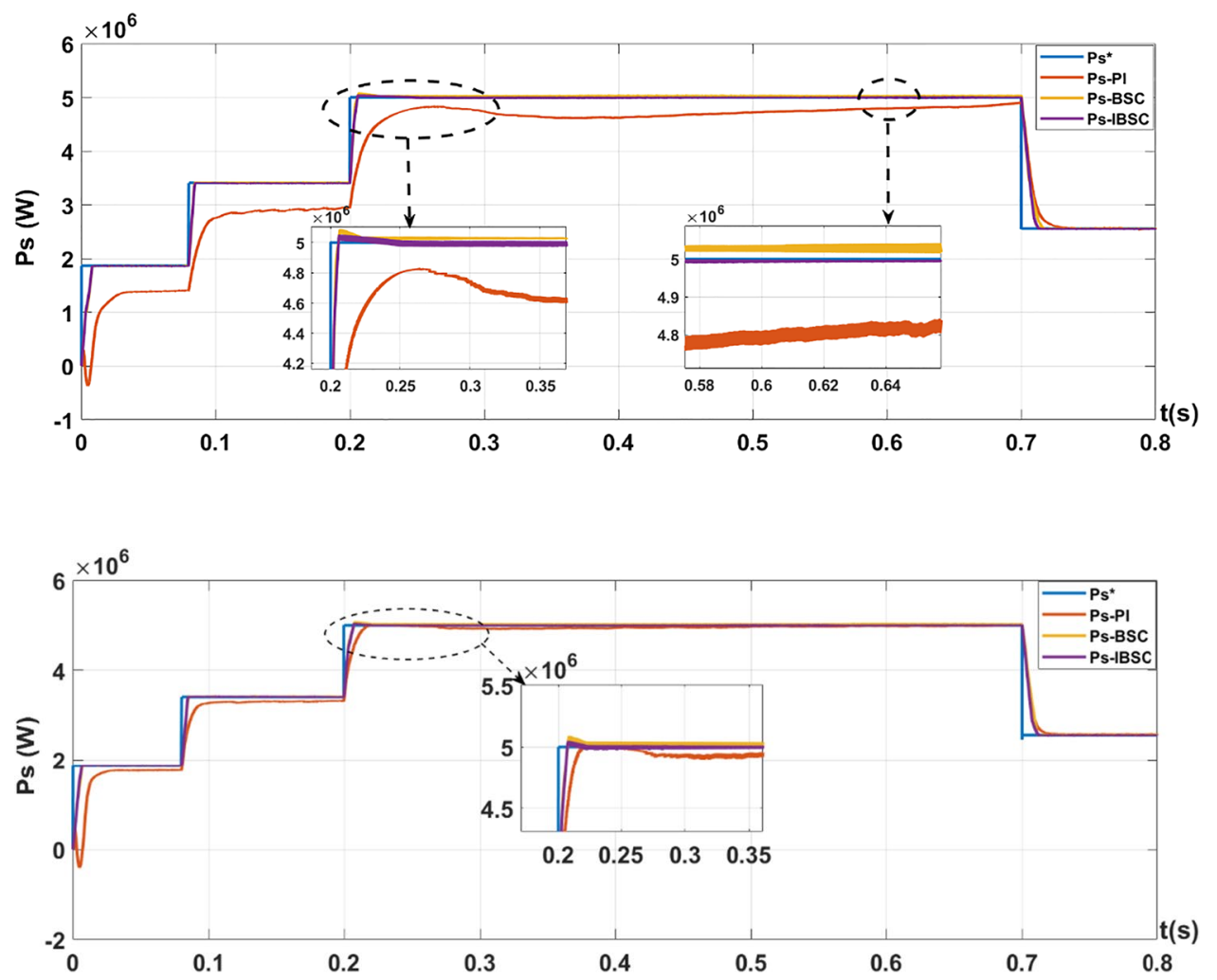

compared to the findings attained by conventional Backstepping and Indirect Vector Control, the overshoot is reduced to $93.62 \%$ and $89.45 \%$, respectively.

- The IBS Control presents better robustness against the generator parameters variation than the Conventional Backstepping and the indirect vector control, respectively. The IBSC ensures better stability, enhances precision and reduces the system response time.

Data Availability No data were used to support this study.

\section{Declarations}

Conflict of Interest The authors declare that they have no conflicts of interest regarding the publication of this paper.

\section{References}

1. Noussi K, Abouloifa A, Katir H, Lachka I (2019) Modeling and control of a wind turbine based on a doubly fed induction generator. 4th World Conference on Complex Systems (WCCS) Ouarzazate Morocco 2019, pp 1-5. https://doi.org/10.1109/ICoCS. 2019.8930738
2. Ahyaten S, Bahaoui J (2020) Modeling of wind turbines based on DFIG Generator. Proceedings, 63:16. https://doi.org/10.3390/ proceedings 2020063016

3. Zgarni I, ElAmraoui L (2021) Design of optimal control of DFIGbased wind turbine system through linear quadratic regulator. Int J Adv Comput Sci Appl (IJACSA) 12(10):708-716

4. Lamnadi M, Trihi M, Bossoufi B, Boulezhar A (2016) Modeling and control of a doubly Fed Induction Generator for Wind Turbine- Generator Systems. Int J Power Electron Drive Syst (IJPEDS) 7(3):973-985, 982-994. https://doi.org/10.11591/ijpeds. v7.i3

5. Mousa HHH, Abdel-Raheem Y, Essam EMM (2021) State of the art perturb and observe MPPT algorithms based wind energy conversion systems: A technology review. Int J Electr Power Energy Syst 126(Part A):0142-0615. https://doi.org/10.1016/j.ijepes. 2020.106598

6. Omar Baba A, Liu G, Chen X (2020) Classification and evaluation review of maximum power point tracking methods. Sustain Futures 2:100020. https://doi.org/10.1016/j.sftr.2020.100020

7. Bouderbala M, Bossoufi B, Lagrioui A, Taoussi M, Aroussi H, Ihedrane Y (2018) Direct and indirect vector control of a doubly fed induction generator based in a wind energy conversion system. Int J Electr Comput Engineering (IJECE) 9(3):1531-1540. https:// doi.org/10.11591/ijece.v9i3.pp1531-1540

8. Kasbi A, Rahali A (2021) () Performance improvement of modern variable-velocity wind turbines technology based on the doublyfed induction generator (DFIG) Materials Today: Proceedings. https://doi.org/10.1016/j.matpr.2021.02.114

9. Cherifi D, Miloud Y (2020) Improvement technique of direct torque control of DFIG based in wind energy conversion system. Glob J Inf Technol Emerg Technol 10(1):022-034. https://doi.org/ 10.18844/gjit.v\%vi\%i.4630

10. Benevieri A, Maragliano G, Marchesoni M, Passalacqua M, Vaccaro L (2021) Induction motor direct torque control with 
synchronous PWM. Energies 14(16):5025. https://doi.org/10. 3390/en14165025

11. Zahedi Abdolhadi H, Arab Markadeh G, Taghipour Boroujeni S (2021) Sliding mode and terminal sliding mode control of cascaded doubly Fed Induction Generator. IJEEE 17(3):1955-1955

12. Chojaa H, Derouich A, Taoussi M, Zamzoum O, Hanafi A (2020) An improved performance variable speed wind turbine driving a doubly fed induction generator using sliding mode strategy. 2020 IEEE 2nd Int. Conf. Electron. Control. Optim. Comput. Sci. ICECOCS, 2020. https://doi.org/10.1109/ICECOCS50124. 2020.9314629

13. Djeriri Y (2020) Robust second order sliding mode control of Doubly Fed Induction Generator for wind energy conversion system. Acta Electrotech Inform 20(3):30-38. https://doi.org/10. 15546/aeei-2020-0017

14. Kelkoul B, Boumediene A (2021) Stability analysis and study between classical sliding mode control (SMC) and super twisting algorithm (STA) for doubly fed induction generator (DFIG) under wind turbine. Energy 214:118871. https://doi.org/10.1016/j. energy.2020.118871

15. Sami I, Ullah S, Ali Z, Ullah N, Ro J-S (2020) A super twisting fractional order terminal sliding mode control for DFIG-based wind energy conversion system. Energies 13(9):2158. https://doi. org/10.3390/en13092158

16. Chojaa H, Derouich A, Chehaidia SE, Zamzoum O, Taoussi M, Elouatouat H (2021) Integral sliding mode control for DFIG based WECS with MPPT based on artificial neural network under a real wind profile. Energy Rep 7:4809-4824. https://doi.org/10.1016/j. egyr.2021.07.066

17. Dbaghi Y, Farhat S, Mediouni M, Essakhi H, Elmoudden A (2021) Indirect power control of DFIG based on wind turbine operating in MPPT using backstepping approach. Int J Electr Comput Eng 11(3):1951-1961. https://doi.org/10.11591/ijece.v11i3

18. El Mourabit Y, Derouich A, El Ghzizal A, El Ouanjli N, Zamzoum O (2020) Nonlinear backstepping control for PMSG wind turbine used on the real wind profile of the Dakhla-Morocco city. Int Trans Electr Energy Syst 30:4. https://doi.org/10.1002/2050-7038. 12297. )

19. Mensou S, Essadki A, Minka I, Nasser T, Bououlid Idrissi B (2018) Backstepping controller for a variable wind speed energy conversion system based on a DFIG. Int J Electr Comput Eng 12(9):598-604. https://doi.org/10.5281/zenodo.1474543

20. Nadour M, Essadki A, Nasser T (2017) Comparative analysis between PI \& Backstepping control strategies of DFIG Driven by Wind Turbine. Int J Renew Energy Res 7(3)

21. Bossoufi B, Aroussi HA, Ziani EM, Karim M, Lagrioui A, Derouich A, Taoussi M (2014) Robust adaptive Backstepping control approach of DFIG generators for wind turbines variable-speed. 2014 International Renewable and Sustainable Energy Conference (IRSEC). https://doi.org/10.1109/irsec.2014.7059885

22. El Malah M, Ba-Razzouk A, Abdelmounim E, Madark M (2020) Integral backstepping based nonlinear control for maximum power point tracking and unity power factor of a grid connected hybrid wind-photovoltaic system. Indones J Electr Eng Inform 8(4):706722. https://doi.org/10.11591/ijeei.v8i4.2327

23. Errami Y, Obbadi A, Sahnoun S (2020) Control of PMSG wind electrical system in network context and during the MPP tracking process. Int J Syst Control Commun 11(2):200-225. https://doi. org/10.1504/IJSCC.2020.106578
24. Chetouani E, Errami Y, Obbadi A, Sahnoun S (2021) Design of optimal backstepping control for a wind power plant system using the adaptive weighted particle swarm optimization. Int J Intell Eng Syst 14(6):125-136. https://doi.org/10.22266/ijies2021.1231.12

25. Taghdisi M, Balochian S (2020) Maximum power point tracking of variable-speed wind turbines using self-tuning fuzzy PID. Technol Econ Smart Grids Sustain Energy 5(1). https://doi.org/ 10.1007/s40866-020-00087-3

26. Chetouani E, Errami Y, Obbadi A, Sahnoun S (2021) Backstepping and indirect vector control for rotor side converter of Doubly Fed-Induction Generator with maximum power point tracking. In: Motahhir S., Bossoufi B. (eds) Digital Technologies and Applications. ICDTA'21, Lecture Notes in Networks and Systems, vol 211, pp 1711-1723. Springer, Heidelberg

27. Baran J, Jąderko A (2020) An MPPT Control of a PMSG-Based WECS with disturbance compensation and wind speed estimation. Energies 13(23):6344. https://doi.org/10.3390/en13236344

28. Xuesong Z, Yongliang Z, Youjie M, Luyong Y, Xia Y, Zhang B (2020) DC bus voltage control of grid-side converter in permanent magnet synchronous generator based on improved second-order linear active disturbance rejection control. Energies 13:4592. https://doi.org/10.3390/en13184592

29. Also M (2015) Modeling and control of a wind system based Doubly Fed Induction Generator: Optimization of the power produced. J Electr Electron Syst 4(1). https://doi.org/10.4172/2332-0796. 1000141

30. Koumba PM, Cheriti A, Doumbia ML, El Moubarek Bouzid A, Chaoui H (2017) Wind turbine control based on a permanent magnet synchronous generator connected to an Isolated electrical network. 2017 IEEE Electrical Power and Energy Conference (EPEC), Saskatoon, SK, pp 1-7. https://doi.org/10.1109/EPEC. 2017.8286224

31. Zhang S, En-Mi Y, Yu Z, Wei-Qi Q (2020) Dynamic Backstepping control for pure-feedback non-linear systems. IMA J Math Control Inf 37(2):670-693. https://doi.org/10.1093/imamci/dnz019

32. Cai-Xue C, Yun-Xiang X, Yong-Hong L (2015) Backstepping control of speed sensorless permanent magnet synchronous motor based on slide model observer. Int J Autom Comput 12(2):149155. https://doi.org/10.1007/s11633-015-0881-2

33. Errami Y, Obbadi A, Sahnoun S, Benhmida M, Ouassaid M, Maaroufi M (2016) Design of a nonlinear backstepping control strategy of grid interconnected wind power system based PMSG. AIP Conference Proceedings, 1758, 030053. https://doi.org/10. 1063/1.4959449

34. Doumi M, Aissaoui AG, Tahour A, Abid M, Tahir K (2016) Nonlinear integral backstepping control of wind energy conversion system based on a Double-Fed Induction Generator. Prz. Elektrotechniczny 92(3):130-135. https://doi.org/10.15199/48.2016. 03.32

35. Adekanle O, Guisser M, Abdelmounim E, Aboulfatah M (2017) Integral Backstepping controller combined with High Gain Observer for the optimization of grid-connected Doubly-Fed Induction Generator. 2017 Int. Conf. Wirel. Technol. Embed. Intell. Syst. WITS 2017. https://doi.org/10.1109/WITS.2017. 7934650

Publisher's Note Springer Nature remains neutral with regard to jurisdictional claims in published maps and institutional affiliations. 